\title{
CAUSAS SOCIALES DE LA MORTALIDAD DURANTE LA INDUSTRIALIZACIÓN VIZCAÍNA (1877-1930) ${ }^{1}$
}

\author{
Mercedes Arbaiza Vilallonga
}

Doctora en Historia

\section{RESUMEN}

En este artículo se aborda la relación entre el control social de la mortalidad y el desarrollo económico a lo largo de la primera industrialización de Vizcaya (1877-1930). Se trata de constrastar las hipótesis relacionadas con los determinantes sociales que explican la presencia de la enfermedad en un colectivo, en el contexto de la primera fase del capitalismo industrial. Para ello se realiza un estudio sobre la contribución de las principales causas de muerte al fuerte descenso de la esperanza de vida producido en el último tercio del s. XIX y a la posterior caída secular de la mortalidad a comienzos del s. XX en el área urbano industrial del Gran Bilbao. A partir de una jerarquización de enfermedades se realiza una evaluación de los factores de riesgo de la población. Se valora la exposición al contagio según condiciones de vivienda, política sanitaria y condiciones higiénicas por un lado, así como el grado de resistencia segun el status nutritivo por otro.

\section{SUMMARY}

The article discusses the relationship between the social control of the mortality and the economic development along the first industrialization of Vizcaya (1877-1930). We want to contrast the hypothesis dealing with the social factors wich explain the reality of the sickness in a group during the firt period of the industrial capitalism. In order to it we report on the contribution of the main causes of the death to the deep fall of the expectation of life produced in the last third period of the XIX c. as well as to the secular fall of the mortality at the beginning of the $\mathrm{XX} \mathrm{c}$. in the industrial urban area of the Great Bilbao. It is done an evaluation of the factors of risk of the population based on an hierarchy of the different illness. It is considered the exposition to the contagion depending on the levels of housing, health policy, hygienic conditions as well as nutritive status.

1 Este trabajo de investigación se enmarca dentro del proyecto de investigación financiado por el Departamento de Educación, Investigación y Universidades del Gobierno Vasco y por la Universidad del País Vasco titulado «Causas sociales de la mortalidad y política sanitaria durante la primera industrialización en la Ría de Bilbao, 1876-1936» durante el curso 1994-1995. 


\section{EL IMPACTO DE LA INDUSTRIALIZACIÓN SOBRE LA ESPERANZA DE VIDA}

La interpretación del proceso de la transición de la mortalidad asocia la caída definitiva de la mortalidad en Europa desde el s. XVIII con la mejora de los niveles de vida y de la misma organización social. Sin embargo, esta relación entre control de la mortalidad y desarrollo económico es controvertida y en absoluto es directa. La historia de la transición de la mortalidad no fue una historia lineal ni progresiva sino que está llena de saltos y de discontinuidades. De hecho fueron muchas las regiones europeas que, tras una primera fase de reducción de la mortalidad ordinaria, experimentaron a mediados del s. XIX una situación de estancamiento e incluso de retroceso en las probabilidades de vivir de la población. La primera fase de la industrialización en la Europa del norte y central tuvo consecuencias claramente regresivas para la salud de la población, tal y como se ha comprobado de forma indirecta a través de la evolución de los niveles de la mortalidad. Es a partir de finales del s. XIX cuando la transición es irreversible.

El País Vasco compartió esta misma experiencia. En esta región se inició ya desde el s. XVIII un cierto control sobre las crisis demográficas de tipo antiguo. Asimismo se produjo una disminución de la mortalidad infantil y ordinaria desde finales del s. XVIII hasta la mitad del s. XIX que se podría identificar como la primera fase de la transición de la mortalidad en el País Vasco ${ }^{2}$. No obstante, desde 1860 hasta 1900 la transición de la mortalidad sufrió un serio retroceso, al menos en la provincia eminentemente industrial, Vizcaya. Como en otras regiones europeas, el proceso de urbanización asociado a la industrialización no sólo frenó una tendencia a la modernización de las pautas demográficas sino que provocó comportamientos regresivos ${ }^{3}$.

En esta provincia, crecimiento económico y explosión demográfica fueron dos caras de la misma moneda. Las unidades de explotación de tipo extensivo, como la minería así como aquellas primeras plantas siderúrgicas que ocupaban a cerca de 6.000 trabajadores al año, generaron una demanda masiva de trabajo e intensos desplazamientos de hombres y mujeres que en poco espacio de tiempo se ubicaron en una pequeña franja territorial alterando profundamente el equilibrio anterior. Estamos ante un modelo de urbanización extremadamente concentrado y construído

2 Veánse los resultados sobre las crisis demográficas en URRUTIKOETXEA, J., (1986), «Mortalidad de crisis en la Guipúzcoa del siglo XVIII. La Guerra de la Convención», Ernaroa, Vol. 1, pp.131-158. Sobre la evolución secular de la mortalidad infantil y juvenil en Vizcaya entre 1775 y 1930 en ARBAIZA, M.(1994a), Estrategias familiares y transición demográfica en Vizcaya, 1825-1930, Tesis doctoral inédita. Universidad del País Vasco, pp. 293-312 y ARBAIZA, M., GuERrero, A., y PAREJA, A., (1995), «La transición de la mortalidad infantil en Vizcaya, etapas y contrastes territoriales» Comunicación presentada a la sesión de «La transición de la mortalidad infantil y juvenil» del IV Congreso de la Asociación de Demografía Histórica, Bilbao.

3 ARbaiza, Guerrero, y PAREJA, (1995), pp. 18-23. 
sobre áreas con escasa tradición urbana a lo largo de los siglos precedentes ${ }^{4}$. Sabemos, por otra parte, que el reemplazo fácil y rápido de mano de obra sostuvo unos niveles salariales insuficientes y llegó a ser un factor dislocador de la organización social resultante 5 .

Para profundizar en esta interrelación entre urbanización/mortalidad en Vizcaya vamos a centrar el análisis en el área urbana que configura el cinturón industrial de Bilbao. Más concretamente, en la comunidad de Baracaldo, un buen ejemplo de población industrial que surgió de forma acelerada alrededor de las grandes plantas siderúrgicas al borde de la Ría del Nervión. Es representativa de un conjunto territorial más amplio, formado por municipios de carácter minero e industrial, y que se extiende en la margen izquierda del Nervión desde Santurce hasta Bilbao ${ }^{6}$. Esta zona pasó de contar con 4.710 habitantes en 1877 a 54.410 habitantes en 1900 y 95.286 en 1930. El ritmo de crecimiento anual fue en todo momento superior al 2 por cien. Estamos, por lo tanto, ante una población eminentemente asalariada, que sufrió los efectos intensos de la industrialización e inmigración sobre la organización del espacio urbano y sobre sus condiciones de vida.

Uno de los indicadores que mejor expresa de forma sintética las repercusiones intensas que tuvieron sobre la población estos dos procesos sociales estrechamente ligados, es la esperanza de vida al nacer. En la tabla 1 se presenta una evolución de este indicador en los distintos cortes temporales de la localidad analizada.

\begin{tabular}{|c|c|c|c|c|c|c|}
\hline & 1877 & 1890 & 1900 & 1910 & 1920 & 1930 \\
\hline Total población & 4.710 & 10.884 & 15.126 & 19.249 & 26.906 & 34.209 \\
\hline$r($ por cien $)$ & $*$ & 6,53 & 4,13 & 2,61 & 3,31 & 2,43 \\
\hline
\end{tabular}


MERCEDES ARBAIZA VILALLONGA

Tabla 1: Esperanza de vida en la zona urbano-industrial vizcaína 1860-19307

\begin{tabular}{lcccccc}
\hline & 1860 & 1877 & 1890 & 1900 & 1910 & 1930 \\
\hline E (0) & 34,6 & 38,0 & 23,9 & 30,4 & 42,4 & 50,3 \\
E (5) & $*$ & 45,2 & 41,6 & 44,8 & 52,2 & 56,5 \\
\hline
\end{tabular}

Como es sabido, 1877 marca el pistoletazo de salida en la carrera de la industrialización en Vizcaya. Pues bien, los datos hablan por sí solos: entre 1877 y 1890, la esperanza de vida disminuyó catorce años. La nueva sociedad emergente alrededor del cinturón industrial de Bilbao manifestó unos comportamientos claramente traumáticos en sus niveles de mortalidad. Además, las probabilidades de vivir de la población en vísperas del boom industrial, no se volvieron a alcanzar hasta 1910. Uno de los efectos sociales de este modelo industrial es un retraso de más de treinta años respecto a la caída definitiva de la mortalidad.

A la luz de los resultados no queda lugar a dudas de que debemos de corroborar la interpretación pesimista que algunos historiadores como M. González Portilla hicieron en los años setenta, recientemente confirmadas por P. Pérez Fuentes ${ }^{8}$, sobre las consecuencias sociales que pudieron ocasionar estos fenómenos distintos pero paralelos de industrialización/urbanización/movimientos migratorios. Los desajustes sociales y el empeoramiento de las condiciones de vida hasta una situación biológicamente límite llevaron a un amplia área urbanoindustrial a una dislocación social, que se tradujo evidentemente en una morbi-mortalidad mayor que en etapas anteriores.

Es difícil deslindar el impacto que tuvo la urbanización sobre la salud de la población del que tuvieron las condiciones económicas de los trabajadores. Es lógico pensar, por un lado, que los efectos de una urbanización descontrolada desde los poderes públicos o mal gestionada desde las mismas empresas produjeron un incremento en la exposición a los factores de riesgo; y, por otro lado, es posible que unas relaciones laborales poco ventajosas para los trabajadores disminuyeron la capacidad

7 Los datos de Baracaldo de 1877, 1890, 1910 y 1930 son de elaboración propia. La esperanza de vida de Baracaldo de 1860 está publicada en GonZÁLEZ UGARTE, M. E. (1994), «Mortalidad e industrialización en el País Vasco, 1860-1930», Boletín de la Asociación de Demografia Histórica, vol XII-1, p.43. Debido al severísimo régimen de mortalidad que se impone entre 1877 y 1900 hemos recogido en el Apéndice 1 y 2, al final, una amplia explicación sobre la metodología aplicada en la estimación de la esperanza de vida y sobre la bondad de las fuentes en lo que respecta a la calidad del registro civil así como con la estructura por edades de los padrones de población utilizados.

8 GONZÁlez PORTILlA, M. (1977), «Los orígenes de la sociedad capitalista en el País Vasco. Transformaciones económicas y sociales en Vizcaya», Saoiak, 1 ; PÉREZ FUENTES, P., (1993), Vivir y morir en las minas, Bilbao, p.276. 
de supervivencia y que, por lo tanto, afectaron a las necesidades más primarias de este colectivo humano. La gran riqueza y pluralidad de aspectos que explican el estado de salud de la población, su exposición al riesgo de enfermar y su capacidad de resistencia, deben de ser analizados para comprender exactamente lo que ocurrió a lo largo de este periodo en el que la población sufre los efectos combinados de asalarización y de concentración geográfica.

Desde este punto de partida, uno de los objetivos que nos proponemos es abordar las consecuencias demográficas que la movilidad y la industrialización tuvieron sobre las condiciones de vida de la población. Se trataría de explicar los factores que directamente contribuyeron al incremento de la mortalidad a finales del s. XIX y que supusieron un retraso en la transición demográfica. Por otra parte, es evidente que a partir de 1890 la lucha contra la muerte consiguió sus primeros resultados. En la tabla 1 podíamos observar como la esperanza de vida muestra una tendencia a aumentar entre 1890 y 1900 y de forma más radical a partir de 1900. En este contexto cronológico nos proponemos como segundo objetivo explicar el conjunto de mejoras sociales que concurren en una comunidad industrial como la de Baracaldo y que explican la caída definitiva de la mortalidad.

\section{APROXIMACIÓN METODOLÓGICA A LAS CAUSAS SOCIALES DE LA MORTALIDAD}

En el hecho vital de la muerte confluyen un haz de decisiones de distinta naturaleza, tanto individuales como de tipo público, que nos ponen al descubierto el grado de organización social y político de una comunidad (avances sanitarios), de elementos culturales (individuales y colectivos) y costumbres alimenticias así como niveles nutricionales que propician una población con mayor o menor capacidad para resistir la enfermedad ${ }^{9}$. En épocas en las que el progreso médico-científico para curar las enfermedades de una población es escaso, el estudio de las causas de mortalidad toma un carácter plenamente social ya que nos acerca a aquellos factores de riesgo que constituían una amenaza para las condiciones vitales humanas. Si queremos

9 La defensa de la tesis del papel determinante del estado nutricional en el descenso moderno de la mortalidad tiene su máximo exponente en la figura de MCKEOWN, T. (1977), El crecimiento moderno de la población, Madrid. Uno de los principales defensores del papel de la sanidad pública como el principal responsable de la transición de la mortalidad es S. PRESTON, (1976) Mortality Patterns in National Populations with Special Reference to Recorded Causes of Death, Nueva York. Un estado de la cuestión de la discusión sobre la transición de la mortalidad veáse en SCHOFIELD, R., y REHER, D. S. (1991), «The Decline of Mortality in Europe», en SCHOFIELD, R.; REHER, D. S., y BIDEAU, A. (Eds.), The Decline of Mortality in Europe, Oxford, Clarendon Press, pp. 1-17; BERnABÉU MESTRE, J., (1991), «Enfermedad y población: Una aproximación crítica a la epidemiología histórica española», Revisiones en Salud Pública, vol. 2, pp. 68-88. 
introducirnos, por lo tanto, en la interpretación sobre la relación entre la mortalidad y su relación con el progreso económico, no nos queda otro camino que aproximarnos al impacto real que tuvieron las enfermedades sobre la población. Las expresiones diagnósticas que informan sobre las causas de muerte serían como el factor inmediato, o si se prefiere, el eslabón entre la mortalidad y los determinantes sociales ${ }^{10}$.

Somos conscientes que resulta complejo y arriesgado establecer una jerarquía entre el conjunto de factores que convergen sobre la mortalidad de una población y el grado de desorganización que se puede intuir a través de los indicadores hasta ahora manejados. Alrededor de la pobreza convergen muchas carencias, tanto nutritivas como medio-ambientales, derivadas éstas últimas de la infravivienda, de la incultura y de los malos hábitos de vida, higiene y alimentación. No obstante, nos ha parecido oportuno, debido a la calidad de los datos que disponíamos, realizar el análisis de la mortalidad por edades y enfermedades con el objeto de jerarquizar dichos factores que explican tanto la fase de dislocación como el impulso de la segunda fase de la transición de la mortalidad, que dura hasta la revolución científico-médica de los años cuarenta.

La cuestión sobre la clasificación de enfermedades a utilizar para un dilatado periodo histórico ha sido uno de los problemas metodólogicos con que nos hemos enfrentado. La más utilizada por los historiadores de la medicina ha sido la Clasificación Internacional del Dr. Bertillon, con sus sucesivas revisiones. Su uso tiene innumerables ventajas. Una de ellas, es su universalidad geográfica que permite hacer comparaciones entre los diversos países desde al menos, principios de siglo hasta ahora. Pero no está exenta de problemas desde el punto de vista de los historiadores de la demografía. Pensamos que el criterio anatómico no es el más adecuado cuando lo que se pretende es explicar los orígenes sociales de la muerte en comunidades bajo patrón de mortalidad de tipo antiguo, es decir, bajo predominio de las enfermedades infecciosas y en ausencia de recursos terapeúticos (antibióticos). Así, nos encontramos con que el primer grupo de dicha clasificación, denominado como Enfermedades Generales, puede llegar a representar el 70 por cien de las causas de muerte. Esta categoría no aporta grandes explicaciones. En el caso de que las enfermedades contenidas en este apartado no se puedan desagregar, los resultados que se desprenden de ella no pueden ser muy concluyentes.

Se ha optado en nuestro caso por seguir la propuesta de Thomas McKeown. Es decir, hemos utilizado una agrupación de las enfermedades según su naturaleza cau-

10 Veáse al respecto la reflexión sobre las posibilidades que la epidemiología histórica ofrece desde la perspectiva de la historia social, en esta línea de relación entre la enfermedad, factores de riesgo y condiciones de vida que realiza BERNABÉU MESTRE, J., (1995), «Enfermedad y Población. Introducción a los problemas y métodos de la epidemiología histórica», Seminari d'estudis sobre la ciència. Scientia Veterum, Valencia, p. 55. 
sal ${ }^{11}$. Este análisis es especialmente adecuado si tenemos en cuenta que las principales causas de enfermedad y muerte, hasta la aparición de los antibióticos en la década de los 40, es de naturaleza infecciosa. Así, hemos diferenciado en primer lugar entre las causas infecciosas y no infecciosas. Es especialmente interesante para nosotros el hecho de que haga una segunda división de las infecciones según la naturaleza de la transmisión, es decir, entre las transmitidas por aire, agua y alimentos o por otros microorganismos. En ausencia de modos eficaces de erradicarlas, los antibióticos, si conocemos la forma de propagación también conoceremos los medios que una sociedad disponía para controlarlas.

En definitiva, esta clasificación permite comprender los mecanismos utilizados para la reducción del contacto con los microorganismos y, por lo tanto, las causas sociales de la enfermedad y de la muerte. No hay que perder de vista que nuestro objetivo es, en última instancia, medir las condiciones de vida y entrever la relación entre unos procesos urbanos como los analizados y un incremento fuerte de la mortalidad infantil y juvenil, así como interpretar la reducción de las enfermedades de este colectivo en relación con los cambios sociales que se desarrollan al hilo de la modernización. En definitiva, se ha optado por utilizar el criterio etiológico (origen de la enfermedad) frente al criterio anatómico como forma más adecuada de evaluar la relación entre el control de la propagación de los microorganismos con el grado de desarrollo económico y social.

\section{LAS ALTERACIONES EN EL RÉGIMEN DE MORTALIDAD LIGADAS A LA URBANIZACIÓN}

Nos hemos aproximado en primer lugar al impacto de la mortalidad por grupos de edades entre la población de Baracaldo. En la tabla 2 se han calculado las tasas específicas de mortalidad (m (x)) $)^{12}$, es decir, se ha establecido una relación entre el número de fallecidos y el total de supervivientes en un momento dado.

\footnotetext{
11 La agrupación de enfermedades y el modo en que se ha asignado cada causa concreta a su grupo, tiene una enorme deuda con el magnífico trabajo realizado por el profesor J. BERNABÉU MESTRE (s.f.), Evolución de la mortalidad en Pego (1838-1936). Análisis semántico-documental, Universidad de Alicante. Dados nuestros limitados conocimientos de medicina, no nos hubiera sido posible realizar este ejercicio sin la ayuda de este trabajo que amablemente nos facilitó, ni de su constante predisposición a resolver las innumerables dudas que surgieron. La clasificación utilizada permite a la vez aislar algunas enfermedades concretas de cada grupo, para hacer un seguimiento individualizado a lo largo del período analizado.

12 Se ha utilizado la estructura por edades de los padrones de población. Una crítica de la fuente se encuentra en el Apéndice II, al final.
} 
MERCEDES ARBAIZA VILALLONGA

Tabla 2: Tasas específicas de mortalidad (por mil) por edades en la zona urbano-industrial vizcaina 1877-1930

\begin{tabular}{|c|c|c|c|c|c|c|c|c|c|}
\hline \multirow{3}{*}{ Edades } & \multicolumn{5}{|c|}{ Tasas específicas de mortalidad } & \multicolumn{4}{|c|}{ Porcentaje de variación $(*)$} \\
\hline & 1877 & 1890 & 1900 & 1910 & 1930 & 1877 & 1890 & 1900 & 1910 \\
\hline & 1011 & 1090 & 1900 & 1910 & 1950 & 1890 & 1900 & 1910 & 1930 \\
\hline $0(* *)$ & 185,19 & 322,22 & 236,30 & 202,49 & 110,57 & 74,00 & $-26,66$ & $-14,31$ & $-45,39$ \\
\hline $1-4$ & 51,59 & 115,66 & 73,70 & 47,81 & 19,93 & 124,20 & $-36,28$ & $-35,13$ & $-58,31$ \\
\hline $5-9$ & 11,64 & 25,59 & 14,46 & 10,79 & 3,47 & 119,96 & $-43,50$ & $-25,39$ & $-67,86$ \\
\hline $10-14$ & 3,71 & 9,36 & 5,89 & 4,40 & 3,25 & 152,21 & $-37,04$ & $-25,36$ & $-26,09$ \\
\hline $15-49$ & 7,34 & 14,58 & 12,53 & 8,27 & 5,29 & 98,65 & $-14,04$ & $-33,99$ & $-36,08$ \\
\hline$>\operatorname{de~} 50$ & 36,90 & 52,93 & 49,20 & 38,96 & 35,80 & 43,43 & $-7,05$ & $-20,81$ & $-8,13$ \\
\hline
\end{tabular}

$\left(^{*}\right)$ Se corresponde con el siguiente cálculo $\left(\left(\mathrm{m}(\mathrm{x})_{\mathrm{t}+1}-\mathrm{m}(\mathrm{x})_{\mathrm{t}}\right) * 100\right) / \mathrm{m}(\mathrm{x})_{\mathrm{t}}$ en donde $\mathrm{t}$ es el año de partida $\mathrm{y}$ $\mathrm{t}+1$ es el año de llegada. (**) Se han corregido las tasas de mortalidad de este grupo de edad según el criterio de subregistro del 4,5 por cien de niños nacidos que mueren antes de cumplir las 24 horas de vida o que nacen muertos.

Aunque entre 1877 y 1890 el estado de salud de toda la población empeoró notablemente en términos relativos, observando el porcentaje de variación, fue el colectivo infantil y juvenil el que más sufrió los efectos de una depauperización de la población. La mayor debilidad de sus organismos y de su sistema inmunológico convierte al colectivo infantil en el grupo de población más sensible a los cambios ecológicos o de ambiente; son las principales víctimas de un cambio en las condiciones higiénico-sanitarias, mediatizadas además por el cuidado de los adultos. Teniendo en cuenta que la familia se movía en los momentos del ciclo vital más delicado con hijos pequeños ${ }^{13}$, no es difícil imaginar los efectos que pudo tener en los cuidados de un niño, en su alimentación y en su higiene, la situación de inestabilidad asociada a la movilidad geográfica, y a la búsqueda de trabajo y de vivienda en la que se encontraba un número importante de habitantes.

En un análisis cruzado de causas de muerte por edades se puede apreciar con qué intensidad afectaron los cuatro grupos de enfermedades a los distintos colectivos de población (tabla 3). Si observamos la evolución de las causas inmediatas de esta situación un tanto límite de la población podemos comprobar que hubo dos grupos de enfermedades que hicieron especial mella en la población. En primer lugar las infecciosas que se transmitían por aire incrementan sus niveles entre 1877 y 1890

13 Veáse ARBAizA, M., (1994b), «Movimientos migratorios y economías familiares en el norte de España (1877-1910)». Boletín de la Asociación de Demografia Histórica, vol XII y XIII, pp. 95-124. 
hasta un 189,3 por cien sobre el conjunto de la población. El impacto que sobre la población infantil y juvenil tuvo este grupo creció en más de un 200 por cien. Pasó de niveles de un 50,93 por mil a 160 niños muertos por mil supervivientes entre la población infantil y de un nivel de 25,4 a 77,5 por mil entre la población juvenil. En segundo lugar, las infecciosas transmitidas por agua y alimentos también sufrieron un intenso incremento en este periodo. Afectaron con especial dureza a los niños menores de un año; el impacto sobre esta población se elevó en más del 200 por cien.

Tabla 3: Tasas específicas de mortalidad (por mil) por edad y grupos de enfermedad en la zona urbano-industrial vizcaina (1877-1930)

\begin{tabular}{lrrrrr|rrrrr}
\hline \multicolumn{7}{c|}{ Infecciosas agua/alimentos } & \multicolumn{5}{|c}{ Infecciosas aire } \\
\hline Edades & 1877 & 1890 & 1900 & 1910 & 1930 & 1877 & 1890 & 1900 & 1910 & 1930 \\
\hline 0 & 13,89 & 42,21 & 30,07 & 31,87 & 27,71 & 50,93 & 160,08 & 101,77 & 71,37 & 28,98 \\
$1-4$ & 11,11 & 19,15 & 10,84 & 5,76 & 3,87 & 25,40 & 77,52 & 45,41 & 28,57 & 8,27 \\
$5-9$ & 2,74 & 2,79 & 1,86 & 2,16 & 0,69 & 6,16 & 14,77 & 7,33 & 4,64 & 0,84 \\
$10-14$ & 0,10 & 1,96 & 1,21 & 1,03 & 0,37 & 2,23 & 3,48 & 2,01 & 1,78 & 0,67 \\
$15-49$ & 0,76 & 1,17 & 0,79 & 0,24 & 0,17 & 3,29 & 7,62 & 7,05 & 4,04 & 2,63 \\
$>$ de 50 & 2,38 & 4,54 & 4,06 & 2,02 & 0,38 & 11,90 & 21,55 & 18,00 & 12,31 & 9,39 \\
Total & 30,98 & 71,81 & 48,83 & 43,07 & 33,19 & 99,91 & 285,02 & 181,57 & 122,71 & 50,79 \\
\hline & Infecciosas otros microorganismos & & No infecciosas (degenerativas) \\
\hline Edades & 1877 & 1890 & 1900 & 1910 & 1930 & 1877 & 1890 & 1900 & 1910 & 1930 \\
\hline 0 & 27,78 & 29,34 & 38,55 & 25,89 & 5,08 & 83,33 & 87,50 & 65,92 & 73,03 & 48,55 \\
$1-4$ & 4,76 & 8,80 & 10,51 & 7,95 & 3,50 & 7,14 & 10,19 & 6,83 & 5,44 & 4,23 \\
$5-9$ & 0,68 & 3,45 & 3,00 & 1,92 & 1,14 & 2,05 & 4,59 & 2,27 & 2,08 & 0,79 \\
$10-14$ & 0,74 & 1,31 & 1,07 & 0,47 & 0,92 & 0,74 & 2,61 & 1,61 & 1,12 & 1,10 \\
$15-49$ & 0,76 & 1,03 & 1,07 & 0,79 & 0,35 & 2,40 & 4,69 & 3,62 & 3,19 & 2,11 \\
$>$ de 50 & 1,79 & 2,84 & 3,19 & 1,44 & 0,77 & 19,05 & 23,44 & 23,95 & 23,19 & 25,01 \\
Total & 36,51 & 46,76 & 57,39 & 38,47 & 11,77 & 114,72 & 133,04 & 104,20 & 108,04 & 81,80 \\
\hline
\end{tabular}

Fuente: Registro Civil de Baracaldo

Para aproximarnos al grado de responsabilidad de cada grupo de enfermedades sobre el total del incremento de la tasa bruta de mortalidad en esta negra etapa de 1877 a 1890 se ha calculado el porcentaje de ascenso de la muerte atribuible a cada 
grupo de enfermedades (tabla 4) ${ }^{14}$. El principal responsable del incremento de la tasa bruta de mortalidad en las primeras oleadas inmigratorias, el grupo de enfermedades transmitidas por aire, contribuyó con un 70 por cien sobre el aumento total de la mortalidad. Alrededor de un 50 por ciento de dicho incremento se concentra en la población infantil y juvenil entre 0 y 4 años que se moría debido a procesos infecciosos de carácter epidémico propios de la infancia así como por enfermedades de tipo respiratorio.

Tabla 4: Contribución de los grupos de enfermedades al incremento de la mortalidad por grupos de edad en la zona urbano-industrial vizcaina entre 1877 y 1890.

\begin{tabular}{l|ccc|ccr}
\hline & \multicolumn{3}{|c|}{ Infecciosas } & \multicolumn{3}{c}{ No infecciosas } \\
\hline \multirow{2}{*}{ Edades } & Agua/Alim & Aire & Otros microorg & degenerativas & sin/clasif(*) & Total \\
& $\cdot$ & & & & & \\
\hline 0 & 4,96 & 19,07 & 0,91 & 2,64 & $-0,79$ & 26,79 \\
$1-4$ & 5,90 & 31,91 & 2,85 & 2,66 & $-1,30$ & 42,02 \\
$5-9$ & 0,13 & 4,67 & 1,44 & 1,39 & 0,00 & 7,63 \\
$10-14$ & 0,76 & 0,37 & 0,18 & 0,69 & 0,00 & 2,00 \\
$15-49$ & 1,02 & 10,86 & 0,67 & 5,71 & $-0,16$ & 18,09 \\
$>$ de 50 & 0,72 & 3,11 & 0,29 & 0,06 & $-0,72$ & 3,47 \\
Total & 13,49 & 70,00 & 6,35 & 13,14 & $-2,97$ & 100,00 \\
\hline
\end{tabular}

Fuente: Registro Civil de Baracaldo. $\left(^{*}\right)$ Se ha recogido esta categoría que viene a explicar la mejoría en la calidad del registro en cuanto a la clasificación de las causas.

No cabe duda que el factor medio-ambiental está potenciando que las enfermedades respiratorias estén muy presentes en el patrón de mortalidad en esta zona. El clima húmedo y frío es propicio para cuadros de resfriados y catarros que acaban degenerando en enfermedades del aparato respiratorio. Pero tampoco cabe la menor duda de que la especial contribución de este grupo de enfermedades a la galopante evolución de la mortalidad infantil está indicando de forma indirecta un tipo de desorden de índole social asociado a la pobreza como es las condiciones de la vivienda. Una alta densidad de población en escaso espacio físico genera un ambiente sumamente cargado, y es un magnífico caldo de cultivo para la propagación de todo tipo de organismos que se contagian a través del contacto humano, las gotas de saliva, etc.

\footnotetext{
14 Para calcular esta contribución se parte de las tasas de mortalidad por grupos de edad y enfermedad en los distintos cortes censales. Una vez estimado el incremento de las tasa de mortalidad por enfermedad y grupo de edad entre ambas fechas, se calcula la relación entre este incremento y el de las tasas brutas de mortalidad entre 1877 y 1890 . Esta relación está expresada en tanto por cien.
} 
El alojamiento en habitaciones de familias completas es un foco de transmisión por excelencia de múltiples enfermedades tanto de carácter epidémico (viruela, sarampión, tosferina) como otras enfermedades que afectan al aparato respiratorio (tuberculosis respiratoria, bronquitis, neumonía etc...). Realmente no es difícil de imaginar los problemas de asentamiento y de habitabilidad de cualquier ciudad que sufre la avalancha de población que se produjo en los pueblos industriales en el último tercio del s. XIX. La ubicación tanto de individuos como de familias enteras se resolvió mal y constituye un mal endémico en estas áreas hasta nuestros días.

En el trabajo de P. Pérez Fuentes sobre los niveles de vida de los mineros de San Salvador del Valle se aporta un valiosísima información sobre estos problemas relacionados con la vivienda, la distribución de alimentos y con la infraestructura urbana a los que vamos a aludir de forma resumida ${ }^{15}$. Rapidez y provisionalidad son las notas que definen la conformación de la trama urbana de esta zona. A pesar de que el sistema de barracones declinó enseguida y se instauró el alojamiento dentro de familias ya asentadas con anterioridad, de forma que se hacían cargo del alojamiento de los recién llegados, el problema de la vivienda en esta zona ha sido históricamente una asignatura pendiente, difícil de resolver. Los primeros barrios se construyeron de forma improvisada, sentando las bases y la infraestructura de lo que constituirá el lugar de asentamiento y de ocupación de las sucesivas generaciones de trabajadores e inmigrantes. Algunas características de las construcciones en este espacio urbano pueden resumirse en la pobreza de los materiales. Las habitaciones eran estrechas, pequeñas, húmedas y mal aireadas.

Por otra parte, la fuerte demanda ha sometido históricamente a este sector a una intensa especulación. El precio de la vivienda era muy caro. Aunque no es nuestro objetivo analizar las estrategias familiares de supervivencia, parece evidente que la disminución de los salarios reales condicionó las opciones en una dirección muy determinada. Por un lado, era necesario reducir gastos familiares y ello pasaba inevitablemente por una solución a todas luces perjudicial para la salud de la población, compartir vivienda mediante la práctica del realquiler de una parte del alojamiento bien a otra familia, bien a huéspedes. Por otro lado, la reducción de la capacidad adquisitiva de los salarios llevó implícita una intensificación del trabajo de todos los miembros de la unidad doméstica según estrategias de acumulación de salarios. Este contexto fomentaba la corresidencia con familiares $u$ otros individuos jóvenes ${ }^{16}$. Las habitaciones eran compartidas por varias familias de forma que se encuentra como práctica común «dormir parejos» o a «cama caliente» que no es sino un eufemismo de compartir varias obreros una misma cama aprovechando el trabajo a turnos de la

15 Veáse PÉREZ FuENTES, P., (1993), pp. 183-202.

16 Las estrategias de corresidencia para una comunidad minera han sido analizadas por PÉREZ FUENTES, P., (1993), pp. 153-76 y para una comunidad industrial por ARBAIZA, M., (1994a), pp. 324-30. 
siderurgia, donde no se lavaban ni aireaban los dormitorios. El hacinamiento de la población y sus consecuencias higiénicas, morales y espirituales provocó ríos de tinta por parte de los contemporáneos. En este sentido los testimonios de los higienistas de la época fueron muy expresivos ${ }^{17}$.

Las enfermedades que se contraen a través de la ingestión de agua contaminada o de alimentos en mal estado ocupan un segundo lugar en el empeoramiento de la salud. El impacto que tuvieron sobre la población infantil y juvenil llegó a contribuir con 13,5 por cien sobre el total del incremento de la tasa bruta de mortalidad. Este grupo de enfermedades apunta hacia desórdenes relacionados con la precaria infraestructura urbana en estas zonas de rápido crecimiento demográfico. Los deficientes servicios de saneamiento y abastecimiento de aguas así como la ausencia de una red de canalización de aguas, de fuentes y lavaderos con agua potable, fueron focos de contagio y de riesgo para enfermedades como la enteritis, gastroenteritis, diarreas y demás infecciones intestinales. La población se abastecía directamente del río Galindo que servía para todo tipo de usos de abastecimiento, lavado y de depósito de residuos. Cuando se carecía de un sistema de aprovisionamiento de agua potable y de una red de evacuación de residuos (un sistema de alcantarillado y de recogida de basuras) evidentemente se incrementa el riesgo de contagio entre la población.

Este mismo grupo está indicando un tercer desorden que viene producido por la disposición de los alimentos en mal estado, derivado a su vez de unas malas condiciones en su suministro y distribución (condiciones higiénicas de los mercados, largas cadenas de distribución sin inspecciones cotidianas, etc.). Sin entrar a valorar el problema de la cantidad de alimentación que los trabajadores podían obtener o la variedad y equilibrio de la dieta, el precario abastecimiento de la población generó en estas zonas urbanas problemas importantes que derivaron en un incremento de las infecciones debido a un consumo en mal estado. No en vano, en los primeros conflictos obreros de esta zona, una de las protestas hacía referencia a las cantinas y a la larga cadena de intermediarios alrededor del suministro de los productos básicos de alimentación que, además de encarecer el precio, sacaban al mercado productos en malas condiciones higiénicas.

17 Fueron varios los contemporáneos que describen con gran minuciosidad y detalle las condiciones de vida de la clase trabajadora en el área minero industrial y que no vamos a reproducir. Cabe destacar las obras de Mariano de ECHEvARría (1894), Higienización de Bilbao; Gumersindo GómEZ (1895), Como se vive y como se muere en Bilbao. Reseña demográfica de la villa. 


\section{CAUSAS SOCIALES DE LA MORTALIDAD DURANTE LA INDUSTRIALIZACIÓN VIZCAÍNA...}

\section{LA CONTRIBUCIÓN DE LAS ENFERMEDADES A LA CAÍDA DE LA MORTALIDAD}

En la última década del s. XIX prácticamente todos los grupos de infección así como las enfermedades degenerativas redujeron sus efectos mortíferos y provocaron un descenso de la tasa bruta de mortalidad (tablas 2 y 3 ). Comienza la caída definitiva de la mortalidad. Entre 1890 y 1930, el impacto de la mortalidad sobre los niños menores de 1 año disminuyó un 65,8 por cien —es decir, se reducen los niveles una media de un 16,45 por cien cada diez años-y un 82,8 por cien en el caso de la mortalidad juvenil —una media de un 20,7 por cien cada diez años- Los grupos de enfermedades presentaron, sin embargo, ritmos distintos en su descenso.

Estamos en la primera etapa de la transición epidemiológica. Entre 1890 y 1930, la contribución de las distintas enfermedades a la caída definitiva de la mortalidad general e infantil pone de relieve el grado de desarrollo social y organizativo de esta comunidad, para ir controlando y atajando la propagación de los microorganismos. Por un lado, la iniciativa consciente de tipo público, encaminada hacia un menor contacto de la población con las fuentes de las enfermedades infecciosas, propició una disminución del contagio. Los defensores de la tesis de la primacía de la organización sanitaria y de la intervención de las autoridades en materia sanitaria y preventiva, argumentarían que ésta es la principal razón del control social de la muerte. Por otro lado, la disminución de la mortalidad debido a enfermedades infecto-contagiosas está estrechamente relacionada con el aumento de las defensas del organismo humano y, por lo tanto, de una mayor resistencia humana a ser invadida por un microorganismo. De esta forma, aunque la intensidad de una enfermedad siga latente en un colectivo, no tiene efectos sobre la tasa de mortalidad. Los defensores del nivel nutricional de una población como condición imprescindible para que se produzca la transición epidemiológica se basan en el vínculo entre nutrición-infección como idea central.

La reducción de los niveles de mortalidad en la última década del s. XIX en esta zona urbano-industrial se explica por la tendencia a disminuir aquellas enfermedades que se transmitían por aire y por agua y alimentación en mal estado, que se redujeron un 36,3 por cien y un 32 por cien respectivamente. Por el contrario, las enfermedades infecciosas transmitidas por otros microorganismos - entre las que se encuentran la meningitis- siguieron una tendencia al alza hasta 1900 . Tal y como reconoce McKweon ${ }^{18}$, aquellas acciones de tipo público que no necesitaron de una colaboración individual cotidiana fueron las que tuvieron unos efectos más rápidos en la disminución de los riesgos de contagio de enfermedades transmitidas por el agua como el cólera, las fiebres tifoideas, diarreas y disenterías y otras patologías propias de situaciones de deficiencia en las servicios de desagües y agua potable.

18 MCKCWEON, T., (1977), p. 140. 
En efecto, la construcción del alcantarillado y la conducción de aguas potables, que se llevó a cabo de forma decidida por las autoridades locales a partir de la amarga experiencia del cólera morbo en 1885 , tuvieron una serie de consecuencias inmediatas sobre la población. Si recordamos las evolución de las tasas de mortalidad específicas de las enfermedades infecciosas por agua (tabla 3), es significativo que todos los grupos de edad experimentaron un descenso similar entre 1890 y 1900 de alrededor de algo más de un 30 por cien; es decir, todos se benefician a la vez de las actuaciones de los poderes públicos en la mejora de equipamientos sanitarios. La gran crisis del cólera en 1885, que afectó con especial intensidad a la población baracaldesa, puso en evidencia las nefastas consecuencias de una carencia de infraestructura en equipamientos sanitarios mínimos -como alcantarillado y suministro de agua potable en fuentes y lavaderos públicos- provocando acciones más decididas de las autoridades locales y provinciales.

Los efectos de estos avances relativos a la infraestructura higiénico-sanitaria son inmediatos ${ }^{19}$. La mejora en la organización urbana tuvo un resultado espectacular al comienzo, pero su contribución a la disminución de la mortalidad no mantuvo la misma intensidad una vez lograda la primera reducción de la exposición a las fuentes de contagio. Según los datos de la tabla 3, mientras que entre 1877 y 1890 el ritmo de descenso fue de un 2,4 por cien cada año (24 por cien decenal) entre 1900 y 1930 fue de un 1 por cien anual (10 por cien decenal). La respuesta de la población menor de un año es una clave explicativa de esta trayectoria. Se puede comprobar que estas mejoras sociales tuvieron especial incidencia sobre la población juvenil entre 1 y 4 años, la más sensible a las enfermedades gastrointestinales. No fue así en los niños menores de 1 año. Las enfermedades infecciosas transmitidas por el agua o alimentos mantuvieron un fuerte impacto sobre este grupo de edad, con tasas de mortalidad específicas de alrededor de un 30 por mil a lo largo de todo el periodo estudiado.

En un estudio desagregado de las enfermedades más importantes, se ha aislado la mortalidad por infecciones gastrointestinales (gráfico 1) de aquellas de carácter epidémico como el cólera, también incluida en este grupo. La mortalidad por gastroenteritis entre la población infantil no llevó la tendencia descendente de otras causas de muerte sino que persistió en unos niveles altos, incluso aumentó algo entre 1900 y 1910; mostró una fuerte resistencia a su reducción, siendo la responsable directa de una alta mortalidad infantil en fechas en las que el patrón de enfermar había experimentado cambios de envergadura.

\footnotetext{
19 En el caso de San Salvador del Valle, se produce también una caída drástica de este tipo de enfermedades una vez que comienza la construcción del alcantarillado en los barrios altos de las minas, tal y como demuestra PÉREZ-FuENTES, P., (1993), p. 209.
} 
Gráfico 1: El impacto de las enfermedades gastrointestinales por grupos de edad (tasas específicas de mortalidad)

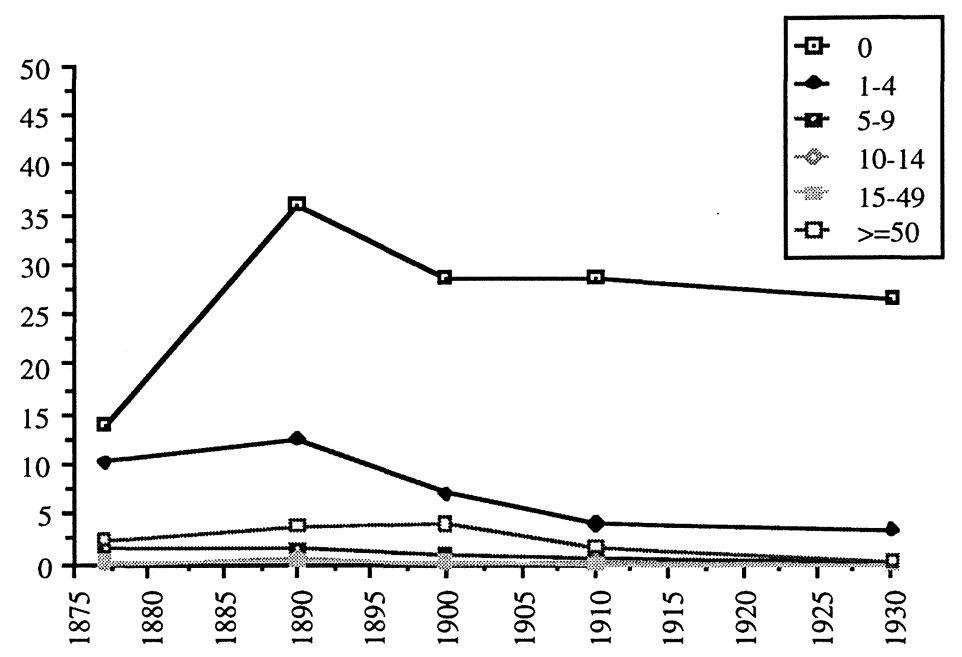

Fuente: Tasas específicas de mortalidad de la tabla 5

El médico Mariano Echevarría, contemporáneo higienista, en su famosa obra $\mathrm{Hi}$ gienización en Bilbao, relacionaba este fenómeno con la incapacidad económica de las familias para alimentar bien a los niños una vez que se eliminaba la leche materna, con estas palabras: «una de las causas [de la mortalidad infantil] es lo brusco de la transición en los niños de la vida en el campo a la vida en la población, teniendo en cuenta las malas condiciones de su habitación, la transición de la alimentación láctea a una alimentación inconsistente y mala después del destete, y la bebida del agua del río, que es la única que surte los barrios obreros» ${ }^{20}$. Este mismo médico denunciará en otro momento la constitución débil de los padres, y sus hábitos de alcoholismo que «contribuyen a que nazcan niños raquíticos, débiles y enfermizos, que al primer síntoma de enfermedad son arrastrados por la muerte» ${ }^{21}$.

20 Reproducida por GONZÁlez PORTILla, M., (1970), La población de la zona minera y de la Ría de Bilbao en el s. XIX. Baracaldo un ejemplo de paso de una demografia de Antiguo Régimen a la revolución industrial, Tesis de licenciatura, Universidad de Valencia, p. 50, tomada a su vez de la obra del citado higienista M. Echevarría.

21 Reproducido por GONZÁLEZ PORTILLA, M., (1970), p. 62. 
Es evidente que en este comportamiento de la mortalidad infantil concurren elementos económicos y culturales difíciles de deslindar. Tal y como expresan los contemporáneos, la persistencia de unas altas tasas de mortalidad infantil está íntimamente relacionada con dos circunstancias: la primera, con la escasez de leche materna y la reducción del tiempo de amamantamiento materno que elimina muchas defensas al niño en su primer año de vida; la segunda, con el delicado momento en que se deja de amamantar al niño y se suministra una alimentación sustitutiva. Hay que tener en cuenta que el control de las infecciones a través de los alimentos entra en el ámbito de las decisiones individuales y que, por lo tanto, son mucho más difíciles de controlar por las autoridades sanitarias del momento.

Se necesitaba, en primer lugar, de unos medios económicos mínimos que facilitaran la elección y que, por lo tanto, posibilitaran alterar dichos comportamientos. Pero además, en la medida en que el cuidado y alimentación de los niños responde también a factores de naturaleza cultural, cualquier medida orientada a su transformación y mejora precisa de una colaboración diaria de cada individuo, en este caso, de cada madre. Los hábitos y costumbres desarrollados alrededor del mundo del cuidado de los niños responde, en gran parte, a toda una tradición transmitida de forma oral de madres a hijas sobre la que es muy difícil incidir y corregir. Una veces por alimentos escasos y en mal estado, otras por unas dietas poco adecuadas que provocaban síndromes de mala absorción en unos seres con un aparato digestivo muy inmaduro, o bien por viejas prácticas populares claramente nocivas para los niños, como las purgas en los momentos de la dentición o las dietas a agua en casos de diarrea, el caso es que las madres cometían numerosas negligencias en el cuidado hacia los niños recién nacidos ${ }^{22}$. Sirva como muestra el testimonio de un médico de Bilbao, G. G. Revilla, que en un artículo del periódico El Liberal, titulado «En defensa del niño», afirmaba, una vez iniciada la transición epidemiológica en 1912:

«Si todavía las madres cuando sus hijos enferman supieran, descendiendo de la inmensa altura de su ignorancia, confesar sus errores y reconocerlos, acudiendo solícitas a la ciencia, sus hijos se curarían; pero persisten y se aferran a sus preocupaciones, confían en la cura espontánea o milagrera de sus hijos y los pierden cuando podían salvarlos con facilidad. Y culpan a los dientes de lo que es su propia obra.» (El Liberal, 11 de julio de 1912).

Hasta que no se crearon los primeros dispensarios en la década de los años veinte, que ejercieron sobre todo como puntos distribuidores de leche materna en condiciones, así como centros educativos sobre el amamantamiento y sobre la utilización de

\footnotetext{
22 PERDiguero GiL, E., (1993), «Causas de muerte y relación entre conocimiento científico y conocimiento popular», Boletín de la Asociación de Demografia Histórica, vol. XI-3, pp. 75-6.
} 


\section{CAUSAS SOCIALES DE LA MORTALIDAD DURANTE LA INDUSTRIALIZACIÓN VIZCAÍNA...}

la alimentación sustitutiva, no se pudo controlar la muerte infantil por enfermedades gastrointestinales. En este caso, el papel de los médicos y de las autoridades sanitarias fue clave en la promoción de nuevos hábitos, y en la vulgarización y difusión de técnicas higiénico-sanitarias ${ }^{23}$. Ello requería de una mejora en la política administrativa, sobre todo en el ámbito de la oferta de servicios sanitarios que tardó en llegar ${ }^{24}$.

En cualquier caso, el principal avance en el control de la mortalidad infantil y juvenil vendría sobre todo asociado a la disminución de las enfermedades transmitidas por contacto humano a través del aire. Se partía de los niveles más altos en las fases más duras y experimentó un proceso de descenso progresivo, continuado y sin interrupción hasta 1930 , con una reducción media de un 30 por cien cada década (recuérdese tabla 3). Su contribución al descenso de la mortalidad infantil y juvenil fue el más importante, de un 50,4 por cien entre 1890 y 1910 y un 46,6 por cien entre 1910 y 1930.

Tabla 5: Tasas especificas de mortalidad por causas de enfermedad

\begin{tabular}{|c|c|c|c|c|c|c|c|c|c|c|c|}
\hline \multirow[b]{2}{*}{ Edades } & \multicolumn{5}{|c|}{ Viruela/sarampión/tosferina } & \multicolumn{6}{|c|}{ Meningitis/Encefalitis/Infec. cerebrales } \\
\hline & 1877 & 1890 & 1900 & 1910 & 1930 & Edades & 1877 & 1890 & 1900 & 1910 & 1930 \\
\hline 0 & 4,63 & 44,27 & 22,74 & 13,94 & 2,29 & 0 & 25,46 & 27,28 & 35,08 & 21,91 & 4,83 \\
\hline $1-4$ & 2,38 & 23,47 & 20,38 & 6,25 & 0,85 & $1-4$ & 3,97 & 7,57 & 9,65 & 7,14 & 3,08 \\
\hline $5-9$ & 0,00 & 4,76 & 2,38 & 0,40 & 0,00 & $5-9$ & 0,00 & 3,12 & 2,89 & 1,68 & 0,89 \\
\hline $10-14$ & 0,00 & 1,31 & 0,13 & 0,09 & 0,00 & $10-14$ & 0,74 & 0,87 & 0,80 & 0,19 & 0,55 \\
\hline $15-49$ & 0,13 & 1,80 & 0,66 & 0,00 & 0,00 & $15-49$ & 0,38 & 0,47 & 0,36 & 0,24 & 0,12 \\
\hline$>$ de 50 & 0,00 & 2,08 & 0,44 & 0,00 & 0,00 & $>\operatorname{de} 50$ & 1,10 & 0,57 & 0,87 & 0,48 & 0,19 \\
\hline T.B.M & 0,42 & 6,30 & 3,97 & 1,30 & 0,13 & T.B.M & 1,56 & 2,63 & 3,09 & 2,01 & 0,65 \\
\hline
\end{tabular}

\begin{tabular}{|c|c|c|c|c|c|c|c|c|c|c|c|}
\hline \multicolumn{7}{|c|}{ Respiratorias infecciosas (Bronquitis/neum/gripe...) } & \multicolumn{5}{|c|}{ Tuberculosis } \\
\hline Edades & 1877 & 1890 & 1900 & 1910 & 1930 & Edades & 1877 & 1890 & 1900 & 1910 & 1930 \\
\hline 0 & 39,35 & 106,03 & 72,09 & 55,10 & 26,69 & 0 & 4,63 & 0,51 & 4,63 & 2,32 & 0,00 \\
\hline $1-4$ & 14,29 & 36,29 & 17,67 & 20,05 & 7,31 & $1-4$ & 4,76 & 2,47 & 2,60 & 1,22 & 0,06 \\
\hline 5-9 & 2,05 & 5,41 & 2,17 & 2,80 & 0,84 & $5-9$ & 3,42 & 1,64 & 2,38 & 1,36 & 0,00 \\
\hline $10-14$ & 0,74 & 1,31 & 0,40 & 0,37 & 0,43 & $10-14$ & 1,48 & 0,65 & 1,07 & 1,31 & 0,25 \\
\hline
\end{tabular}

23 BERNABÉU MESTRE, J. (1991), «Enfermedad y población: Una aproximación crítica a la epidemiología histórica española», Revisiones en Salud Pública, vol.2. pp. 78-9.

24 Sobre la evolución de las actuaciones administrativas desde el Estado en materia sanitaria, ver el capítulo «La lucha contra la mortalidad» de PÉREZ MOREDA, V. (1980), Las crisis de mortalidad en la España interior, siglos XVI-XIX, Madrid, Siglo XXI, especialmente el apartado «La legislación sanitaria y la lucha antiepidémica».pp. 418-33. 
MERCEDES ARBAIZA VILALLONGA

\begin{tabular}{|c|c|c|c|c|c|c|c|c|c|c|c|}
\hline $15-49$ & 1,14 & 3,16 & 2,58 & 1,52 & 1,29 & \multicolumn{2}{|l|}{$15-49$} & 02 & 3,7 & 2,52 & 1,29 \\
\hline$>$ de 50 & 6,55 & 17,96 & 14,66 & 10,49 & 8,63 & \multicolumn{2}{|c|}{$>\operatorname{de} 50$} & 76 & 2,7 & 1,73 & 0,77 \\
\hline T.B.M & 4,32 & 12,36 & 7,62 & 6,57 & 3,24 & \multicolumn{2}{|c|}{ T.B.M } & 76 & 3,0 & 1,96 & 0,83 \\
\hline \multicolumn{6}{|c|}{ Gastroenteritis } & \multicolumn{6}{|c|}{ Apoplejía/derrame cerebral } \\
\hline Edades & 1877 & 1890 & 1900 & 1910 & 1930 & Edades & 1877 & 1890 & 1900 & 1910 & 1930 \\
\hline 0 & 13,89 & 36,03 & 28,53 & 28,55 & 26,69 & 0 & 9,26 & 15,96 & 11,95 & 16,60 & 2,03 \\
\hline $1-4$ & 10,32 & 12,51 & 7,26 & 3,98 & 3,32 & $1-4$ & 1,59 & 3,40 & 1,63 & 1,30 & 0,06 \\
\hline $5-9$ & 1,37 & 1,48 & 0,72 & 0,64 & 0,25 & $5-9$ & 0,68 & 1,48 & 0,52 & 0,32 & 0,00 \\
\hline $10-14$ & 0,00 & 0,65 & 0,13 & 0,37 & 0,06 & $10-14$ & 0,00 & 0,65 & 0,13 & 0,09 & 0,00 \\
\hline $15-49$ & 0,25 & 0,33 & 0,38 & 0,02 & 0,01 & $15-49$ & 0,38 & 0,83 & 0,41 & 0,32 & 0,10 \\
\hline$>$ de 50 & 2,38 & 3,59 & 4,06 & 1,83 & 0,34 & $>\operatorname{de} 50$ & 11,19 & 2,65 & 2,90 & 4,33 & 2,92 \\
\hline T.B.M & 1,91 & 3,54 & 2,54 & 1,74 & 1,02 & T.B.M & 2,12 & 1,91 & 1,16 & 1,36 & 0,46 \\
\hline \multicolumn{7}{|c|}{ Ap. Circulatorio } & \multicolumn{5}{|c|}{ Muerte Violenta/Accidente } \\
\hline Edades & 1877 & 1890 & 1900 & 1910 & 1930 & Edades & 1877 & 1890 & 1900 & 1910 & 1930 \\
\hline 0 & 0,00 & 1,54 & 4,63 & 2,99 & 2,03 & 0 & 2,31 & 1,03 & 0,39 & 1,00 & 0,51 \\
\hline $1-4$ & 0,00 & 1,08 & 1,08 & 0,65 & 0,60 & $1-4$ & 0,79 & 1,08 & 0,65 & 0,57 & 0,48 \\
\hline $5-9$ & 0,00 & 0,82 & 0,41 & 0,64 & 0,25 & $5-9$ & 0,68 & 0,66 & 0,72 & 0,32 & 0,10 \\
\hline $10-14$ & 0,00 & 0,65 & 0,67 & 0,28 & 0,43 & $10-14$ & 0,00 & 1,09 & 0,40 & 0,19 & 0,12 \\
\hline $15-49$ & 0,13 & 0,70 & 0,61 & 0,79 & 0,67 & $15-49$ & 1,14 & 1,07 & 1,28 & 0,75 & 0,40 \\
\hline$>$ de 50 & 0,00 & 8,32 & 9,29 & 7,50 & 8,48 & $>$ de 50 & 1,19 & 1,89 & 1,45 & 0,58 & 1,29 \\
\hline T.B.M & 0,07 & 1,52 & 1,57 & 1,49 & 1,57 & T.B.M & 0,99 & 1,10 & 1,02 & 0,59 & 0,46 \\
\hline
\end{tabular}

Debido a la heterogeneidad de enfermedades que componen este grupo, en la tabla 5 se ha recogido el papel desagregado de las principales enfermedades y que muestran con mayor precisión las causas sociales de la reducción de la mortalidad. Asimismo se ha calculado de nuevo la contribución de las principales enfermedades al ascenso (tabla 6a) y al descenso secular de la mortalidad (tabla 6b). Para ello se ha estimado el porcentaje del cual es responsable cada una sobre la reducción de la mortalidad total, de forma que se puede cuantificar y jerarquizar el papel de cada enfermedad en la caída de la mortalidad. 
CAUSAS SOCIALES DE LA MORTALIDAD DURANTE LA INDUSTRIALIZACIÓN VIZCAÍNA...

Tabla 6a: Contribución de algunas enfermedades más importantes al incremento de la mortalidad entre 1877 y 1890 (\% sobre el total del incremento) ${ }^{25}$

\begin{tabular}{lcccc}
\hline Edades & Viruela+Saramp+Tosf. & Gastrit/enteritis & Infec.Respiratorias & Meningitis \\
\hline 0 & 6,67 & 4,00 & 11,98 & 0,90 \\
$1-4$ & 11,97 & 2,64 & 14,12 & 2,53 \\
$5-9$ & 2,47 & 0,11 & 1,82 & 1,61 \\
$10-14$ & 0,51 & 0,26 & 0,18 & $-0,01$ \\
$15-49$ & 4,27 & 0,20 & 5,14 & $-0,21$ \\
$>$ de 50 & 0,94 & 0,31 & 4,48 & $-0,4$ \\
\% Total & 26,83 & 7,52 & 37,72 & 4,42 \\
\hline
\end{tabular}

La disminución progresiva de los procesos infecciosos se debió en una primera fase a un control de aquellas enfermedades de carácter epidémico que afectaban especialmente a la población infantil. Estamos haciendo referencia a la viruela, sarampión, tosferina y escarlatina, que pasaron de tener un carácter endémico en las primeras fases de la industrialización (tabla 5) hasta su práctica desaparición como causa de muerte en 1910. A pesar de los avances en las prácticas de prevención que se habían introducido en Vizcaya a lo largo del siglo s. XIX, mediante inoculación y profilaxis, la concentración y hacinamiento en la década de los años ochenta fue un ambiente propicio para que estas enfermedades se cebaran de nuevo en la población infantil. Sin embargo, la reacción social no tardó en producirse. Los conocimientos higiénico-sanitarios de las autoridades políticas y sanitarias del País Vasco estaban lo suficientemente desarrollados como para poner en marcha una serie de medidas encaminadas a reducir el contacto de la población con la enfermedad. No en vano, existía en la sociedad vasca toda una tradición en el control de la propagación de estos virus, que tiempo atrás había tenido un gran éxito ${ }^{26}$. Además de viejas costumbres, como el aislamiento de los enfermos y la creación de cordones sanitarios, las

\footnotetext{
25 Sobre el método de cálculo veáse nota 14.

26 Veánse los documentos que publica RAMOS CALVO, P. M. (1988), «Aportaciones de Euskalherria a la inoculación antivariólica», Actas de II Congreso Mundial Vasco, Bilbao, pp. 286-300, sobre el papel transcendental que ejerció en el País Vasco a finales del s.XVIII la Real Sociedad Bascongada de Amigos del País, en su sección de medicina, en la introducción de la inoculación antivariólica. Los efectos de la divulgación de esta práctica por los pueblos del Pais Vasco se reflejaron en la disminución de la mortalidad infantil y juvenil a lo largo de la primera mitad del s. XIX, tal y como se ha demostrado en ArbaizA, M. (1994b), pp. 292-300 y ArbaizA, Guerrero y PAREJA (1995), p. 9.
} 
campañas de vacunación de la población habían logrado reducir los efectos mortíferos de la viruela.

La acción de prevención y profilaxis por parte de los higienistas contra este tipo de enfermedades lograron prácticamente erradicar este tipo de epidemias. A pesar de que, tal y como se quejaba el médico higienista García Vergara, chocaron en todo momento con dos obstáculos: una especial resistencia y desidia por parte de la población urbano-industrial ante las propuestas de la Junta de Sanidad 27 , y una segunda dificultad, tan importante como la anterior y en gran medida insalvable, las características del alojamiento en el que se encontraban instaladas las familias y los hijos de los trabajadores.

Tabla 6b: Contribución de algunas enfermedades más importantes a la caida de la mortalidad (\% sobre el total del descenso)

\begin{tabular}{|c|c|c|c|c|c|c|c|c|}
\hline \multirow{3}{*}{ Edades } & \multicolumn{4}{|c|}{ Viruela/Sarampión/Tosferina } & \multicolumn{4}{|c|}{ Respiratorias infecciosas } \\
\hline & 1890 & 1900 & 1910 & 1890 & 1890 & 1900 & 1910 & 1890 \\
\hline & 1900 & 1910 & 1930 & 1930 & 1900 & 1910 & 1930 & 1930 \\
\hline 0 & 6,71 & 4,35 & 3,83 & 5,12 & 11,01 & 9,45 & 11,10 & 10,63 \\
\hline $1-4$ & 2,57 & 21,31 & 7,17 & 9,08 & 18,15 & $-5,20$ & 18,57 & 12,10 \\
\hline $5-9$ & 1,92 & 3,18 & 0,52 & 1,78 & 2,76 & $-1,09$ & 2,64 & 1,70 \\
\hline $10-14$ & 0,81 & 0,04 & 0,10 & 0,37 & 0,59 & $-0,07$ & 0,01 & 0,23 \\
\hline $15-49$ & 5,44 & 4,35 & 0,00 & 3,32 & 3,44 & 7,56 & 0,36 & 3,50 \\
\hline$>$ de 50 & 1,36 & 0,50 & 0,00 & 0,68 & 3,44 & 2,56 & 0,80 & 2,32 \\
\hline \multirow[t]{2}{*}{$\%$ total } & 18,83 & 33,73 & 11,63 & 20,36 & 39,39 & 13,30 & 33,48 & 30,48 \\
\hline & \multicolumn{4}{|c|}{ Gastroenteritis } & \multicolumn{4}{|c|}{ Meningitis } \\
\hline \multirow{2}{*}{ Edades } & 1890 & 1900 & 1910 & 1890 & 1890 & 1900 & 1910 & 1890 \\
\hline & 1900 & 1910 & 1930 & 1930 & 1900 & 1910 & 1930 & 1930 \\
\hline 0 & 2,58 & 1,07 & 2,79 & 2,25 & $-1,92$ & 6,54 & 5,74 & 2,89 \\
\hline $1-4$ & 5,05 & 4,76 & 1,87 & 3,91 & $-2,32$ & 3,31 & 6,15 & 2,01 \\
\hline $5-9$ & 0,61 & 0,12 & 0,54 & 0,46 & $-0,18$ & 1,92 & 1,13 & 0,82 \\
\hline $10-14$ & 0,35 & $-0,36$ & 0,36 & 0,16 & $-0,05$ & 0,74 & $-0,32$ & 0,07 \\
\hline $15-49$ & $-0,12$ & 2,38 & 0,05 & 0,60 & $-0,60$ & 0,89 & 0,50 & 0,65 \\
\hline$>\operatorname{de} 50$ & $-0,18$ & 2,18 & 1,56 & 1,03 & $-0,20$ & 0,35 & 0,28 & 0,11 \\
\hline$\%$ total & 8,30 & 10,16 & 7,17 & 8,41 & $-4,07$ & 13,76 & 13,5 & 6,55 \\
\hline
\end{tabular}

27 PÉREZ-FuENTES, P., (1993), p. 207. 


\section{CAUSAS SOCIALES DE LA MORTALIDAD DURANTE LA INDUSTRIALIZACIÓN VIZCAÍNA..}

Era imposible económicamente realizar cambios drásticos en las condiciones de habitabilidad que propiciaban enfermedades de tipo respiratorio. De todas formas, la experiencia anterior no fue baldía y para 1910 prácticamente habían dejado de ser una causa de muerte entre la población infantil tal y como se observa en el gráfico 2 .

Entre las enfermedades infecciosas transmitidas por aire, aquellas patologías que afectan al sistema respiratorio tuvieron una importancia fundamental en la caída de los niveles de la mortalidad. Las enfermedades respiratorias de carácter ordinario como la bronquitis, neumonía, gripe (gráfico 3), o incluso la tuberculosis, descendieron de forma ininterrumpida. Según la tasa específica de mortalidad de este grupo de enfermedades, cada veinte años se redujeron los niveles a la mitad, pasando de un 12,36 por mil en 1890 a un 6,57 por mil en 1910 , y a un 3,24 por mil en 1930 . La disminución de la mortalidad entre los niños menores de 5 años contribuyó con cerca de 30 por cien al total del descenso de la mortalidad entre 1890 y 1900 , se redujo bastante entre 1900 y 1910 y volvió a contribuir con casi un 30 por cien entre 1910 y 1930. A lo largo de todo el período fue este grupo de enfermedades uno de los principales componentes de las oscilaciones de la mortalidad, tanto en el fuerte ascenso entre 1877 y 1890 (tabla 6a) como en el descenso entre 1890 y 1930 (tabla 6b). La elevada responsabilidad en las alteraciones de la tasa bruta de mortalidad confiere a este grupo una importancia especial en la interpretación de la transición sanitaria.

Gráfico 2: Impacto de las enfermedades infantiles infecciosas: viruela, sarampión y tosferina (Tasas específicas de mortalidad por mil por grupos de edad)

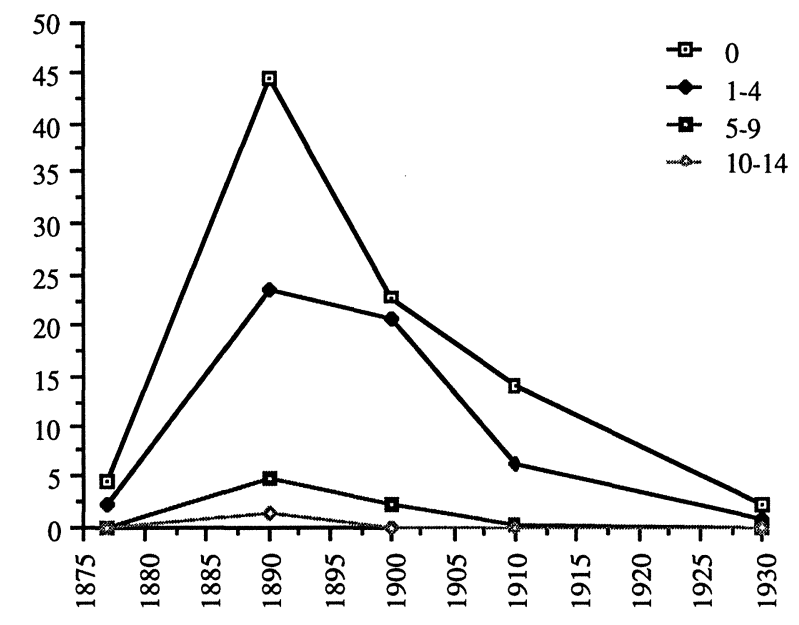

Fuente: Tasas específicas de mortalidad de la Tabla 5 


\section{Gráfico 3: Impacto de las enfermedades respiratorias infecciosas}

(Tasas específicas de mortalidad por mil por grupos de edad)

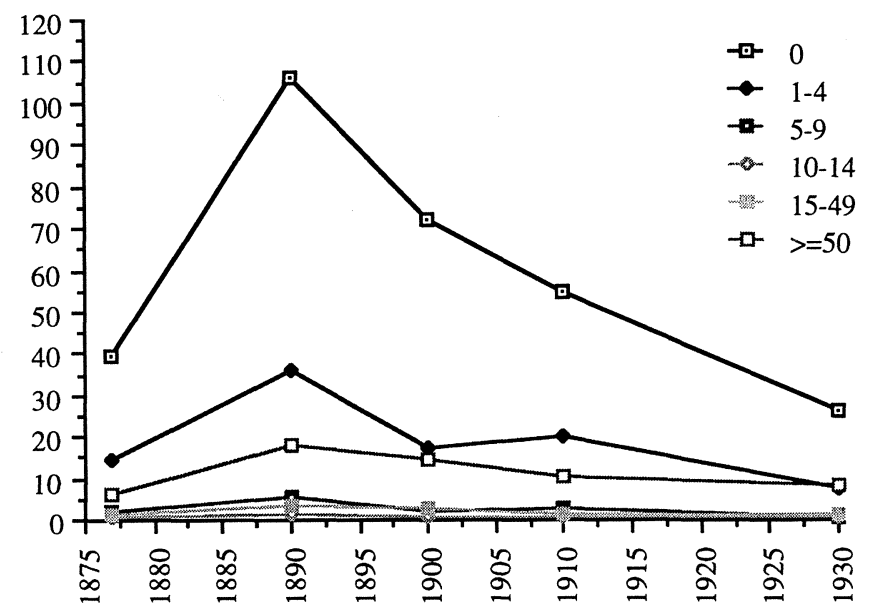

ruente: lasas específicas de mortalidad de la Tabla 5

Sabiendo que hoy en día están muy extendidas entre la población las patologías relacionadas con la complicaciones respiratorias de tipo bronquítico y neumónico, no podemos mantener la tesis de que este tipo de enfermedades del aparato respiratorio desaparecieran sino que, en todo caso, dejaron de ser tan mortíferas para la población. Según la información que tenemos, no tuvieron un tratamiento médico curativo hasta que se extendieron los antibióticos en la década de los años cuarenta. Por lo tanto, la reducción de este grupo precisa de una reflexion, siempre difícil, sobre los factores que explican las enfermedades de tipo respiratorio. Cabe preguntarse si se debió a una mejora sanitaria entre la población, es decir, se consiguieron unos ambientes más salubres y una mejoría en los hábitos de higiene, o si fue una mejora en el nivel de vida de la población los factores que influyeron en la bajada gradual de uno de los principales motivos de muerte entre la población urbano-industrial. Los factores que explican su reducción son bastante más complejos y heterogéneos que los de las infecciosas por agua o las epidémicas infantiles. 


\section{EL CONTROL SOBRE LA EXPOSICIÓN A LOS FACTORES DE RIESGO}

\section{a) El medio ambiente y el problema de la vivienda}

Las informaciones respecto a posibles mejoras en las condiciones sanitarias e higiénicas de la población son contradictorias. La escasez de vivienda fue un hecho común en aquellas ciudades industriales europeas que crecieron rápidamente al calor de oleadas de inmigrantes ${ }^{28}$. Tal y como G. González Martínez ${ }^{29}$ pone de relieve en su estudio sobre el problema de la vivienda en Vizcaya en la década de los años veinte, la situación del alojamiento era especialmente aguda en los municipios del cinturón industrial de Bilbao. Ciudades con un crecimiento demográfico desmesurado, como el de Bilbao y la margen izquierda, generaron una demanda fortísima de viviendas y un desajuste de su precio respecto a la capacidad adquisitiva de un trabajador medio.

Sabemos que una de las consecuencias de este mal social, el hacinamiento, perduró a lo largo de mucho tiempo. Una de las claves de esta situación descansa en las condiciones de la gestión de la construcción. En la medida en que este sector económico estuvo promocionado por la iniciativa privada, las empresas constructoras debían de buscar la rentabilidad de su negocio, como cualquier otro sector económico regulado por el mercado; así, la oferta de viviendas estuvo dirigida hacia sectores económicos con capacidad adquisitiva ${ }^{30}$. Por otra parte, la mayoría de los inmuebles eran propiedad de un reducido colectivo que propiciaba un sistema de alquiler claramente gravoso para la población. La especulación provocó un problema social endémico. Un parque de viviendas escaso y caro generó la cohabitación de varias generaciones o incluso varias familias en una misma habitación. El problema era así percibido por el periódico El Liberal en 1924:

«Según se computan las personas que se dedican a ello con especialidad, es muy probable que haya en Bilbao más de 6.000 familias preocupadas por la dificultad de la vivienda, y más de 30.000 familias en los centros industriales de Vizcaya. Aparte de la espantosa mise-

\footnotetext{
28 BURneTT, J. (1991), «Housing and the Decline of Mortality», en SCHOFIELD, R.; REHER, D. S. y BIDEAU, A. (Eds.), The Decline of Mortality in Europe, Oxford, Clarendon Press. pp. 158-76.

29 GONZÁleZ MARTínEZ, G. (1988), «Aportaciones al estudio del problema de la vivienda en Vizcaya durante la dictadura de Primo de Rivera», en A.A.V.V., 25 años de la Facultad de Filosofia y Letras. II Estudios de Geografia e Historia, Bilbao, Universidad de Deusto. pp. 716-30.

30 El caso ya estudiado de Bilbao es paradigmático al respecto. A pesar de la temprana urbanización del primer ensanche no se construyeron las viviendas planificadas debido al alto precio con se proyectaron. Mientras tanto, riadas de población llegaban a la ciudad y se asentaban en los suburbios al borde del antiguo casco urbano, en condiciones infrahumanas.
} 
ria en que viven otros pobres, cobijadas en casuchas de madera, en arcos de puentes, en lavaderos, en asilos nocturnos, etc. $»^{31}$

La percepción de este problema por parte de los distintos sectores sociales y desde valoraciones distintas, pone de relieve la magnitud y las diversas consecuencias que podía ocasionar. Así, por ejemplo, la reflexión desde sectores nacionalistas sobre algunas consecuencias para la población se realizaba desde la conculcación de una de las señas de identidad genuinas de lo vasco, la familia como ámbito de orden y paz social:

\footnotetext{
«Las malas viviendas son la causa inmediata de la muerte de muchísimas personas, el mensajero de la mayor parte de las enfermedades, de los humores atrabilarios y de la disolución de la familia vasca, tan firme, arraigada y potente en nuestros días» 32 .
}

Sectores de la burguesía, por su parte, apelando al mantenimiento de los principios más básicos de la moralidad también expresan la necesidad de acabar con esta lacra social que es el hacinamiento «a fin de que acaben las explotaciones escandalosas, las aglomeraciones, germinadoras de enfermedades; las promiscuidades de sexos y edades, corruptores de la moral» ${ }^{33}$.

La cuestión del alojamiento suscitó muchos argumentos para su mejora pero quizá el más importante fuera el precio de las rentas y alquileres, que incidía en gran medida en la carestía de la vida. La solución vendría de una intervención decidida del Estado, que no llegó nunca a producirse con la suficiente contundencia hasta que surgieron algunas iniciativas como «La Ley de Casas Baratas» del 10 de Octubre de 1924, en donde se dejaba en manos de los municipios la resolución del problema ${ }^{34}$. Esta ley facilitaba la construcción de barriadas completas para trabajadores.

En resumen, se podría afirmar que el alojamiento y vivienda de la población fue una asignatura pendiente del proceso de urbanización en Vizcaya hasta fechas ya muy avanzadas ${ }^{35}$. Difícilmente pudo ser la amplitud de espacio por familia un factor de disminución del contagio o infección. Las iniciativas para atajar el problema del hacinamiento fueron bastante tardías; cronológicamente, estas actuaciones se dieron cuando la intensidad de las enfermedades respiratorias había descendido sensible-

31 Cita reproducida por GonZÁleZ MARTíNEZ, G., (1988), p. 718.

32 El Obrero Vasco-Euzko Langilla, 16-5-1925 reproducido por GONZÁLEZ MARTíNEZ (1988), p. 721.

33 El Liberal, 20-1-1927 reproducido por GONZÁLEZ MARTíNEZ, G., (1988), p. 721.

34 GONZÁLEZ MARTínEZ, G., (1988), p. 727.

35 Algunas excepciones, como la iniciativa desarrollada en el barrio para trabajadores de Iralabarri a principios del s. XX, de corte higienista que, en cualquier caso, no fue más que una realidad aislada hasta la década de los años veinte. 
mente. Además, fueron a todas luces insuficientes para erradicar un problema de fuertes magnitudes en el conjunto de las ciudades que crecieron en la Ría.

La evolución de una enfermedad como la meningitis es una muestra evidente de que el problema de la alta densidad de población persistió (gráfico 4), teniendo en cuenta que la extensión del microorganismo de la meningitis necesita de una gran concentración de huéspedes humanos para su propagación. Si tomamos la intensidad de esta enfermedad como un indicador del grado de densidad de la población y, por lo tanto, de las condiciones de alojamiento, se puede comprobar que las tasas de mortalidad específica entre la población infantil y juvenil no dejaron de crecer hasta 1900. Su desarrollo está en relación con las oleadas de inmigración; cabe recordar que entre 1880 y 1890 se produjo una primera inmigración a Baracaldo, al calor de la primeras plantas siderúrgicas, y entre 1895 y 1900 una segunda llegada masiva de población agudizó el problema de la concentración de población ${ }^{36}$.

Gráfico 4: Impacto de la meningitis

(Tasas específicas de mortalidad por mil por grupos de edad)

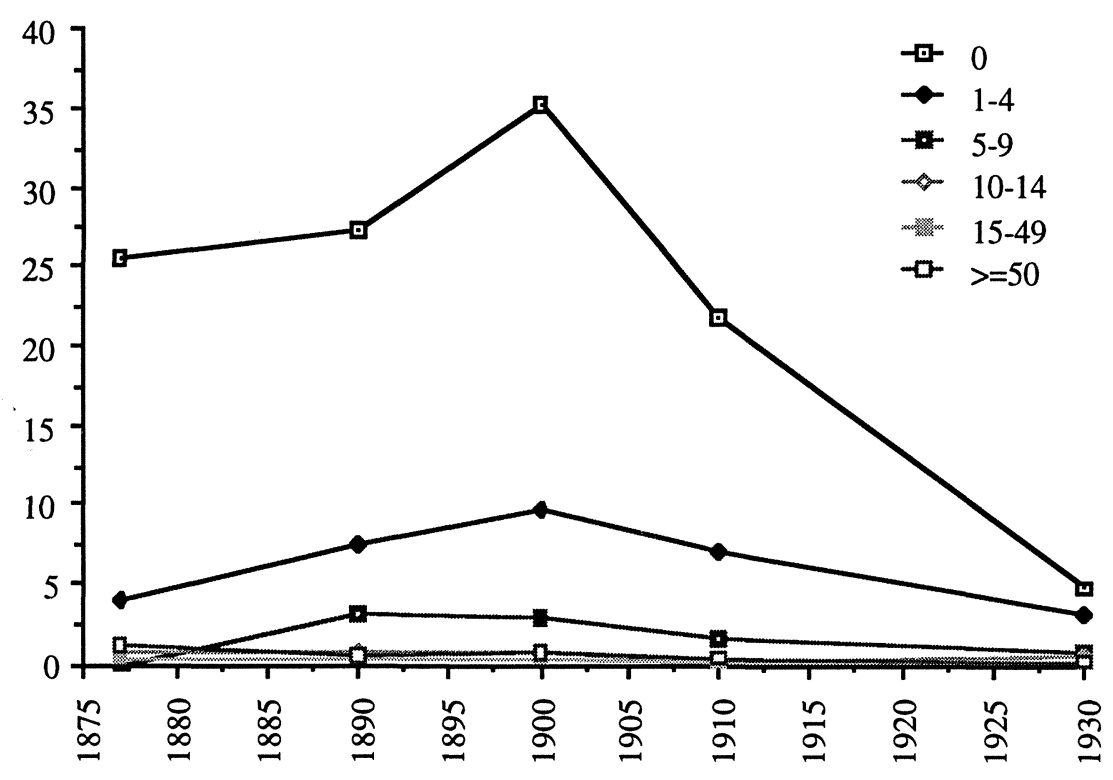

Fuente: Tasas específicas de mortalidad de la tabla 5

36 ARbaizA, M., (1994a), p. 392. 


\section{b) Las políticas de salud pública: un balance desigual}

La reducción de enfermedades epidémicas como la viruela, sarampión y tosferina o la misma meningitis, que llegaron a contribuir a la disminución de la mortalidad entre 1900 y 1910 con un 33,73 por cien y un 13,76 por cien, respectivamente, respondía en todo caso a factores socio-educacionales relacionados con una progresiva transformación en hábitos y costumbres de limpieza y salubridad de la población.

En este sentido, es necesario reconocer la transcendental labor de los higienistas a finales del s. XIX y principios del s. XX. El papel que desempeñó este colectivo de médicos como intermediarios entre quienes sufrían directamente unas condiciones de vida miserables, la población trabajadora, y quienes decidían y organizaban la vida de la comunidad, el poder político representado por las autoridades provinciales y locales, pudo ser socialmente clave para comprender una parte de la transición sanitaria. Sin ánimo de reiterar las funciones que ejercieron, ya analizadas por P. Pérez Fuentes ${ }^{37}$, queremos destacar algunos aspectos de su labor social, debido a la especial incidencia que pudieron tener en la reducción de algunas enfermedades que demandaban una colaboración de las voluntades individuales.

Nos referimos en primer lugar a su papel como educadores y divulgadores de medidas higiénicas, nuevos hábitos de vida y de trabajo. Tuvieron muy claro que la higienización de la sociedad era un instrumento de regeneración social, y no ahorraron esfuerzos en desarrollar toda una serie actividades orientadas a la difusión de prácticas sociales que disciplinaran a la población y transformaran sus hábitos de vida. Los canales de difusión social fueron múltiples: incidieron en los programas educativos relacionados con la higiene pública y privada, elaboración de cartillas higiénicas, conferencias médicas en las asociaciones obreras, organizaciones filantrópicas, escritos en la prensa obrera, etc.

Se alzaron además como grupo de opinión y denuncia exigiendo una mayor intervención a los ayuntamientos y a la Diputación. Se realizaron toda una serie de estudios estadísticos en donde se recogía un diagnóstico y denuncia de las condiciones de la población. Siempre desde una concepción muy moralizadora de la sociedad, se reivindicó con constancia y tenacidad la disciplina para quienes constituyen un recurso fundamental en el progreso de cualquier país, su mano de obra. Fueron una fuente de inspiración para las políticas sociales del momento. La Comisión de Reformas Sociales constituye un buen ejemplo de esto desde su doble función de inspección y desarrollo de las normativas sobre higiene pública.

37 Las aportaciones de PÉREZ-FuENTES, P. (1991), «El discurso higienista y la moralización de la clase obrera en la primera industrialización vasca», Historia Contemporánea, vol. 5, pp. 127-56, sobre el discurso y el papel social de estos médicos ha sido recientemente tratado en un artículo de obligada referencia en el análisis de este colectivo. 
Ahora bien, la transición sanitaria debe de ser también explicada a partir de los avances realizados en la red de hospitales y, por lo tanto, el incremento en la oferta de camas hospitalarias para la población enferma. A principios de siglo se creó el Hospital Civil de Bilbao, el único centro del todo el área urbano industrial de la Ría que acogía a enfermos, además de pequeños dispensarios directamente financiados por los trabajadores de las grandes empresas que cumplían más las labores de alimentar y cuidar de las personas enfermas que las propiamente terapéuticas ${ }^{38}$. Se sabe que el número de camas fue en todo momento escaso y que los servicios de estos centros fueron irregulares, dependiendo en gran medida de las condiciones laborales de cada empresa y de las negociaciones de los trabajadores.

Aunque la preocupación por la extensión de las enfermedades respiratorias estuvo muy extendida entre la opinión pública, las soluciones por parte de la administración fueron sumamente tardías como para explicar su caída. Hasta 1912 no se creó el primer dispensario o sanatorio especializado en tuberculosis, el Sanatorio de Górliz, apoyado a partir de 1915 por el centro «Ledo», la única institución antituberculosa hasta 1930, año en el que se construyó el sanatorio «Santa Marina» especializado en enfermedades respiratorias ${ }^{39}$. La estructura hospitalaria y dispensarial, que contribuyó de forma determinante a resolver la labor preventiva y profiláctica respecto de estas enfermedades, no se desarrolló hasta el periodo 1937-1957.

La reducción de la mortalidad por vía de una mejora de la organización de la comunidad y de los cambios culturales en materia higiénico-sanitaria, explican fundamentalmente la reducción del riesgo de contagio de la población relacionado con el hacinamiento y con la profilaxis ante la infección. Sin embargo, en el caso de la población que nos ocupa, comprobamos que la principal contribución a la reducción de la mortalidad viene de una serie de enfermedades infecciosas difíciles de atajar simplemente por medios preventivos y que biomédicamente están relacionados con el status nutricional. A la luz de los resultados sobre la contribución de las enfermedades a la transición de la mortalidad, cabe barajar la hipótesis de que existía una relación importante entre el papel de las enfermedades respiratorias, en los niveles de la mortalidad, y el estado nutricional de la población como posible explicación, tanto de su ascenso entre 1877 y 1890 como en el proceso de caída progresiva desde principios del s. XX.

\footnotetext{
38 PÉREZ-FUENTES, P., (1993), p. 197.

39 Veánse algunos hitos en la lucha antituberculosa en Vizcaya en VILlanUEVA EDO, A. (1988), «Las instituciones de la lucha antituberculosa en Vizcaya (1882-1957)», Actas II Congreso Mundial Vasco, sección II, vol.1, Bilbao, pp. 340-72.
} 


\section{LA ALIMENTACIÓN Y EL STATUS NUTRITIVO DE LA POBLACIÓN}

No cabe duda que el cuadro de enfermedades de esta población urbano-industrial presenta profundas semejanzas con los resultados que obtuvo McKweon para Inglaterra ${ }^{40}$. En el caso inglés también fueron las enfermedades respiratorias las que más contribuyeron a que los niveles de la mortalidad se redujeran de forma sustancial, lo que condujo a dicho autor a sostener que la mejora de la alimentación de la población fue, en última instancia, la responsable principal del descenso secular de la mortalidad.

Los médicos higienistas de aquel momento, testigos de excepción de la salud de la población, se inclinan por esta tesis cuando afirman, por ejemplo, que «una alimentación poco nutritiva, cuya consecuencia es la «miseria fisiológica», es preámbulo de la tisis y favorece el desarrollo de la tuberculosis» ${ }^{41}$. Por todo ello no podemos dejar de plantear la hipótesis de que una mejora del nivel nutricional y, en definitiva, del nivel de vida, pudo hacer menos mortíferas algunas de estas enfermedades, aun sabiendo la gran dificultad que entraña delimitar en poblaciones históricas la influencia de los niveles nutricionales sobre la infección y sobre la mortalidad.

Parece un hecho indiscutible que existe una estrecha relación entre niveles de nutrición-sistema inmunológico-enfermedades infecciosas. Está comprobado que una población mal nutrida es una población predispuesta y mucho más sensible a enfermedades infecciosas. Una vasta literatura científica ha concluido, a partir de los estudios sobre poblaciones actualmente subdesarrolladas, que la malnutrición agrava la mayor parte de los procesos infecciosos debido a una acción sinérgica entre ambas. El mecanismo de interacción entre nutrición e infección pasa por una reducción de las defensas inmunológicas del organismo, de forma que una inadecuada alimentación provoca una menor resistencia para combatir su intensidad y duración. Las consecuencias son una mayor prolongación e intensidad de la infección y, por lo tanto, el organismo debe de utilizar mayor cantidad de reserva energética para combatir la infección y reparar los anticuerpos, así como otros procesos de inmunización. Esta reacción conlleva una pérdida de peso durante la enfermedad que si no es repuesto debidamente, genera un organismo debilitado en estado carencial de vitaminas y de otros nutrientes y, por lo tanto, más sensible en la próxima infección.

Ahora bien, también es cierto que esta relación está siendo cuestionada, o por lo menos matizada, desde varias perspectivas ${ }^{42}$. Las poblaciones estudiadas elegidas según el criterio de malnutrición coinciden con situaciones de pobreza general, en

\footnotetext{
40 MCKWEON, T., (1977), p. 66-7.

41 Cita del médico M. Echevarría recogida por GonZÁleZ PORTILLA, M., (1970), p. 54

42 Veáse LIVI-BACCI, M. (1988), Ensayo sobre la historia demográfica europea. Población y alimentación en Europa, Barcelona, pp. 46-67.
} 
donde convergen múltiples causas de mortalidad difíciles de deslindar: unas condiciones ambientales e higiénicas desfavorables y, por lo tanto, proclives para el surgimiento y difusión de enfermedades, la infravivienda y la incultura concurren casi siempre en un mismo colectivo. Es, por consiguiente, casi imposible medir la influencia neta de la nutrición sobre la enfermedad, y mucho más en poblaciones históricas en donde se conoce mucho peor la composición de la dieta.

Otro obstáculo es determinar el umbral de nutrición por debajo del cual comienza a acelerarse una reacción negativa entre la infección y la resistencia de la energía acumulada por el organismo. Tal y como demuestra M. Livi-Bacci, solamente en casos de desnutrición grave la sinergia entre nutrición-infección actúa de forma implacable sobre el organismo y la mortalidad tiene, entonces, unos efectos devastadores, mientras que los niños moderadamente mal nutridos reaccionan ante la infección de forma similar que los niños bien nutridos. La dificultad estriba en medir los niveles de malnutrición por debajo de los cuales se produce esta interacción negativa. Además, teniendo en cuenta que una deficiente nutrición del organismo es también una consecuencia o efecto de un ambiente proclive a las infecciones, debido a que cualquier proceso infeccioso genera dificultades en la absorción de los alimentos y, por lo tanto, agrava el estado de la malnutrición, las dificultades para establecer una relación de causalidad en una única dirección entre nutrición e infección y mortalidad son evidentes ${ }^{43}$.

Por último se ha comprobado que no todas las enfermedades infecciosas están directamente relacionadas con la malnutrición. Si contrastamos la tabla 7 , ya publicada por algunos autores ${ }^{44}$, en donde se recoge la influencia del nivel nutritivo en algunos procesos infecciosos, con las principales enfermedades de la población urbanoindustrial que contribuyeron tanto al incremento de la mortalidad en las primeras fases como a su reducción a partir de finales del s. XIX (tablas 5 y 6), podemos sacar algunas conclusiones sobre la existencia de una relación entre un estado nutricional deficiente de la población analizada y su respuesta positiva a determinadas infecciones.

43 LUNN, P. G. (1991), «Nutrition, Immunity, and Infection», en SCHOFIELD, R.; REHER, D. S., y BIDEAU, A. (Eds.), The Decline of Mortality in Europe, Oxford, Clarendon Press, pp. 131-45. Este autor profundiza en la relación entre ambas variables en los dos primeros años de edad de los niños y fundamentalmente en las consecuencias de las diarreas sobre los organismos infantiles.

44 Veáse LiVI-BACCI, M., (1988), p. 63; LUNN, P. G., (1990), p. 137. 
MERCEDES ARBAIZA VILALLONGA

Tabla 7: Influencia del status nutritivo sobre enfermedades infecciosas

\begin{tabular}{llll}
\hline Categoría & Definitiva & Variable & Ligera \\
\hline Bacteriana & Tuberculosis & Difteria & Tifus \\
& Diarrea bacteriana & Stafilococus & Peste \\
& Cólera & Streptococos & Tétanos \\
& Lepra & & \\
& Pertussis & & \\
& Infecciones respiratorias & & Viruela \\
& Sarampión & Gripe & Fiebre amarilla \\
Víricas & Diarrea rotavirus & & ARBO \\
& Infecciones Respiratorias & & Encefalitis \\
& Herpes & & Malaria \\
Parasitarias & Parásitos intestinales & Giardia & \\
& Trypanosomiasis & Filariasis & \\
& Leishmaniasis & & \\
Fungal & Schistosomiasis & & \\
& Cándida & Mould toxins & \\
Otras & Aspergillus & & \\
& & Sífilis & \\
\hline
\end{tabular}

Fuente: LuNN, P. G., (1990), p.137.

Se puede observar que los procesos infecciosos respiratorios están directa y definitivamente relacionados con el estado nutricional de la misma. Recordar que este grupo fue responsable de un 37,72 por cien del incremento de la mortalidad entre 1870 y 1890 . En la siguiente década, entre $1890-1900$, contribuyó a la disminución de la mortalidad con un porcentaje de un 33,39 por cien. Entre 1900 y 1910 el descenso de la mortalidad se debió en un 13,3 por cien al descenso de este grupo; y por último, entre 1910 y 1930 la mortalidad descendió en una tercera parte, 33,48 por cien, debido a estos procesos infecciosos.

El gran impacto que tuvieron las enfermedades respiratorias en la población infantil tanto mediante un ascenso, como después en un descenso de la mortalidad, pone de manifiesto que los niños estuvieron afectados por un status nutricional deficiente. Las carencias nutritivas y calóricas infantiles se explican por la sinergia escaso alimento-infección. La escasa alimentación sustitutiva de la leche materna, que aporta defensas al niño en sus primeros meses, está agravando la mortalidad infantil y poniendo de manifiesto el círculo vicioso de mala alimentación del niño y de la 
madre que le amamanta ${ }^{45}$. Por otro lado, al ser la población más proclive a ser víctima de las epidemias y, por lo tanto, constantemente necesitados de los nutrientes mínimos para superarlas, la escasez o irregularidad de la alimentación produce, en cualquier proceso infeccioso, una progresiva desnutrición y una debilidad crónica.

En última instancia, esta relación entre mortalidad y status nutricional conduce ineludiblemente a la hipótesis sobre la influencia que pudo tener la evolución de los niveles de vida de la clase trabajadora, y más concretamente de los salarios reales o capacidad adquisitiva del colectivo de la población asalariada y sus posibilidades de supervivencia. Según esta hipótesis, el incremento de la mortalidad infantil y juvenil entre 1877 y 1890 por determinados procesos infecciosos como la bronquitis, neumonía o gripe significaría, indirectamente, que se está produciendo una reducción en su capacidad de consumo y alimentación de la población y un deterioro en el estado nutricional de la población. Asimismo, al tener este grupo de enfermedades respiratorias un peso explicativo de un tercio del descenso de la mortalidad entre 1890 y 1930, significa apelar a una mejora de la capacidad de consumo y de alimentación de las familias de los trabajadores como otro factor explicativo importante de su reproducción biológica.

\section{ALGUNAS CONCLUSIONES}

1. Si consideramos que el estado de salud y la intensidad de la mortalidad son indicadores relevantes de las condiciones de vida de la población, se deben de interpretar las consecuencias sociales inmediatas de la industrialización en la Ría de Vizcaya en términos pesimistas. El empeoramiento de las condiciones de vida, así como un inadecuada urbanización, produjeron tanto un incremento del riesgo de contagio como un deterioro de la salud física, estrechamente relacionado con una menor resistencia a cualquier infección. Los cambios que se produjeron en el cuadro de enfermedades delatan los fuertes costos sociales de la industrialización y de la urbanización, que confirman las tesis de la dislocación social. El precio a pagar fue el retraso de más de cuarenta años en la modernización del patrón de mortalidad.

2. El papel fundamental que tuvieron las enfermedades de tipo respiratorio en las variaciones de los niveles de mortalidad y, en definitiva, en la esperanza de vida de la población trabajadora, induce a relacionar la mortalidad con el grado de resistencia de la población a la enfermedad, es decir, con el estado nutricional de la pobla-

45 Sobre la incidencia de la mala salud de las madres trabajadoras sobre la futura salud de su prole véase el ejemplo italiano en BRESCHI, M., y POZZI, L., (1992), «Un problema di demografia differenziale: mortalità infantile e condizione socio-economica», Actas del II Congreso Italo-Iberico di Demografia Storica, Savona, pp. 409-33. 
ción. La historiografía ha demostrado que la industrialización vasca conllevó una pérdida del poder adquisitivo de los trabajadores en una primera fase hasta 1890 . Habría que profundizar en esta relación entre salarios reales, ingresos familiares y empeoramiento fisiológico de la población infantil. Posiblemente la malnutrición constituyó un factor de agravamiento de las condiciones de supervivencia de la población infantil, además de otras condiciones íntimamente unidas a la pobreza como la ignorancia, la mala higiene y los hábitos culturales de alimentación y cuidado negligente de los niños.

Asimismo las causas de muerte que más contribuyeron a la caída de la mortalidad desde que comenzó la transición epidemiológica apuntan hacia las infecciones transmitidas por aire, especialmente las respiratorias, como las que más responsabilidad tuvieron con un 30,48 por cien entre 1890 y 1930 . Las series sobre salarios reales industriales publicados para la principal empresa de Baracaldo ${ }^{46}$ muestran que la capacidad de consumo mejoró para el colectivo de trabajadores con cierto grado de cualificación a partir de 1890, y para el conjunto de los trabajadores a partir de 1902. Es lógico pensar que la resistencia de la población a las infecciones respiratorias incrementó, siendo una causa explicativa importante, que no la única, de esta primera fase de la transición epidemiológica en esta comunidad industrial.

3. La responsabilidad de las enfermedades epidémicas infantiles así como las infecciones transmitidas por aire como la meningitis, está directamente relacionada con el factor hacinamiento, vivienda y la cultura higiénico-sanitaria de la población. Ha permitido valorar el grado de influencia que tuvo el factor exposición de la población a la enfermedad en este proceso de lucha contra la muerte en el medio urbano-industrial. Concretamente, las epidemias infantiles (viruela, sarampión y tosferina) fueron el segundo grupo en orden de importancia en las variaciones de la mortalidad infantil y juvenil, contribuyendo con un 26,83 por cien al incremento de la mortalidad entre 1877 y 1890 y con un 20,36 por cien al descenso de la tasa bruta de mortalidad entre 1890 y 1930.

A falta de estadísticas sobre el estado de la vivienda, los testimonios de la época dejan entrever que no se produjo una mejora de las condiciones de habitabilidad hasta los años veinte, y no se puede considerar, por lo tanto, como un factor que influyera en los inicios de la transición sanitaria. La reducción de este conjunto de enfermedades sólo se explica por una serie de cambios en los hábitos y costumbres de la población. La influencia del pensamiento de los médicos higienistas así como sus acciones de tipo socio-educacional tuvieron una serie de repercusiones en el

46 PÉrez CASTroviejo, P. M. ${ }^{a}$, (1992), Clase obrera y niveles de vida en las primeras fases de la industrialización vizcaína, Madrid, pp. 161-62; FERNÁNDEZ DE PINEDO, E. (1992), «Beneficios, salarios y nivel de vida obrero en una gran empresa siderúrgica vasca, Altos Hornos de Vizcaya (1902-1927). Una primera aproximación», Revista de Historia Industrial, vol.1. p. 46. 
aprendizaje de la prevención y profilaxis, es decir, en la disminución de la exposición a algunas enfermedades. Aunque es difícil valorar la contribución de los médicos sobre la cultura sanitaria de la población, ya que no tuvieron responsabilidad administrativa, se puede intuir que ejercieron un papel importante a través de las medidas impulsadas para erradicar las enfermedades epidémicas, relacionadas con la organización de la higiene pública.

No obstante, la incidencia sobre los hábitos y sobre la organización de la higiene privada precisó de una labor educativa y cultural muy lenta, como cualquier transformación cultural que precise de la cooperación voluntaria de cada individuo. En este sentido, en la medida en que la mortalidad infantil mostró una fuerte resistencia a ceder o superar algunas infecciones como la gastroenteritis, que no acabaron de ceder a pesar del progreso económico de los años veinte, constatamos que las cuestiones que dependieron de decisiones individuales precisan un «tempus» distinto. Fueron factores culturales sobre el cuidado adecuado de los niños y la alimentación sustitutiva la causa principal del retraso en el descenso de la mortalidad entre este grupo de niños menores de 1 año.

4. La intervención sanitaria fue tardía y respecto algunas enfermedades más importantes, como las infecciones respiratorias, prácticamente nula. A excepción de la red de saneamientos que produjo una inmediata reducción del riesgo de contraer infecciones por consumo de aguas contaminadas, las diversas instancias políticas actuaron con retraso y escasa eficacia a la hora de atajar aquellas causas sociales de la enfermedad.

\section{APÉNDICES}

\section{Apéndice I. Crítica del Registro Civil de Baracaldo}

El Registro Civil en España presenta una serie de problemas en su elaboración que precisa de una crítica previa anterior a su utilización indiscriminada. El método indirecto utilizado en la elaboración del registro en sus comienzos, a partir de la información recopilada en las registros parroquiales, suele generar problemas de subregistro de difuntos, sobre todo en la población infantil. Hemos realizado por ello una aproximación a la validez y calidad de la fuente respecto a la inscripción de difuntos en la localidad elegida como objeto de estudio.

Somos conscientes de un problema de subregistro inherente a la fuente del registro civil, que no considera a los niños de menos de 24 horas como personas legales y, por lo tanto, no susceptibles de ser registrados ni como nacidos ni como posterior- 
mente muertos. Es este un problema irresoluble hasta bien pasada la década de los 30 en el que las estadísticas oficiales empiezan a computarlo en sus datos ${ }^{47}$.

Otro de los principales problemas en la calidad del registro es el subregistro de niños menores de 1 año, y en especial los muertos por causas endógenas en el primer mes de vida. Para comprobar la fiabilidad de las partidas consultadas hemos realizado una validación de los datos mediante el estudio de la composición de la mortalidad infantil menor de un año. Se ha calculado la estructura de la mortalidad infantil según la edad de defunción, es decir, se ha descompuesto en mortalidad neonatal —ocurrida en el primer mes de vida - y mortalidad postneonatal -ocurrida entre el primer mes y antes del decimosegundo mes de vida - . Los resultados recogidos en la tabla 1 aportan criterios para evaluar su validez.

Tabla 1: Composición de la mortalidad infantil en Baracaldo

\begin{tabular}{ccccccc}
\hline & \multicolumn{3}{c}{ Estructura interna } & \multicolumn{3}{c}{ Peso de mortalidad neonatal (*) } \\
\hline & m.neonatal & m.postneonatal & T.M.inf. & m.neonatal & m.postneonatal & T.M.inf. \\
\cline { 2 - 7 } 1877 & 54,70 & 82,05 & 136,75 & 44,77 & 55,23 & 100,00 \\
1890 & 45,99 & 169,34 & 215,33 & 31,69 & 68,31 & 100,00 \\
1900 & 35,14 & 128,48 & 163,62 & 35,43 & 64,57 & 100,00 \\
1910 & 27,68 & 104,01 & 131,69 & 38,41 & 61,59 & 100,00 \\
1930 & 16,00 & 70,14 & 86,15 & 43,43 & 56,57 & 100,00 \\
\hline
\end{tabular}

(*) Peso de la mortalidad neonatal sobre la tasa de mortalidad infantil corregida (niños muertos de 0 años +muertos antes de las 24 horas+ nacidos muertos)

Precisamente, es interesante comprobar que la mortalidad neonatal en las primeras fases del registro (1877), que suelen ser el periodo más conflictivo, muestra el nivel más elevado, alcanzando más del cincuenta por cien del total de niños nacidos. Esto confirma la validez de la fuente desde sus comienzos. Una vez corregida la tasa de mortalidad infantil con el subregistro pertinente, estimando en cada año censal alrededor de un 5\% de nacidos muertos y los muertos antes de las 24 horas de vida, el peso de la mortalidad en el primer mes de vida oscila entre los 30 y 40 niños sobre cada 100 niños muertos antes del primer año. La conclusión que se desprende de los resultados obtenidos de la mortalidad neonatal es que el Registro Civil de Baracaldo reúne las condiciones para un análisis de los niveles de mortalidad con garantía de fiabilidad.

47 GómEZ REDONDO, R. (1992), La mortalidad infantil española en el siglo XX, Madrid,.p. 9. 


\section{Apéndice II: Estimación de la esperanza de vida}

Para hallar la esperanza de vida se han construido las tablas de mortalidad abreviadas referidas a las probabilidades de morir de una generación ficticia. La construcción corresponde al análisis transversal realizado por medio de una observación del número de difuntos por grupos de edad en un período de tres años alrededor del año censal.

La construcción de las tablas de mortalidad implica el cálculo de las probabilidades de morir por cohortes de edad, que en este caso son de cinco años (5qx), excepto en el primer grupo en el cual se han desagregado el de 0 años (q0) y el de 1 a 4 (4q1). Los cocientes de mortalidad por grupos de edad (qx) se han calculado de forma indirecta aplicando un coeficiente de conversión a las tasas específicas por edad o $\mathrm{m}(\mathrm{x})$. Las tasas específicas por edad se obtienen, a su vez, dividiendo el número de difuntos, en nuestro caso la media de los tres años alrededor de la fecha censal, entre el stock de población de cada grupo de edades; este último dato nos lo aporta la estructura de la población de los padrones.

Como es sabido, la conversión de las tasas específicas en cocientes de mortalidad es una de las dificultades en la construcción de las tablas de mortalidad, ya que es necesario establecer una relación aritmética entre ambos. De todos los métodos indirectos que proponen una relación funcional entre tasas de mortalidad y probabilidades de muerte, se ha decidido aplicar el método Greville ${ }^{48}$. Una vez calculadas las probabilidades de morir por grupos de edad se han hallado las otras series probabilísticas necesarias para construir la tabla de mortalidad: $1(x)$ o probabilidad de supervivencia y $\mathrm{d}(\mathrm{x})$ o calendario según la relación $\mathrm{q}(\mathrm{x})=\mathrm{d}(\mathrm{x}) / \mathbf{l}(\mathrm{x})$

Otro de los problemas que genera la construcción de las tablas de mortalidad a partir de una generación ficticia es la necesidad de contar con unos censos o padrones que permitan obtener una estructura de población correcta, en los que no se produzca un subregistro de niños. En este caso, hemos utilizado los padrones de población informatizados para los años de 1890, 1900, 1910 y 1930 de Baracaldo. Para las tablas de mortalidad de 1877 se han utilizado los datos de estructura de la población del censo de población de 1877 elaborado por el Instituto Geográfico y Estadístico y publicados por el INE.

Dado el severísimo régimen de mortalidad que muestra la esperanza de vida de Baracaldo en 1890, se ha intentado eliminar cualquier sospecha sobre los efectos de un posible subregistro en la estructura por edades en el censo, que suele afectar al grupo entre 0 y 4 años, minimizando así los $\mathrm{m}(\mathrm{x})$ que son la base de las tablas de mortalidad. Debido a la importancia que tiene la mortalidad de este colectivos en el

48 Tal y como se explica en SHRYOCK, S. H., y SIEGEL, J. S. (1977), The Methods and Materials of Demography, New York, p. 255. 
resultado de la esperanza de vida, se han realizado varios ajustes a las tablas de mortalidad.

En primer lugar se ha procedido a calcular los cocientes de mortalidad de 0 (qo) y de 1a 4 años (4q1) a partir de las generaciones reales de nacidos, es decir, calculando la probabilidad de morir de cada generación de nacidos a diferentes años de edad entre los 0 y 4 años, según los nacidos y difuntos recogidos en el Registro Civil entre 1877 y 1930. Los resultados se han aplicado directamente a la tabla de mortalidad. Dada la excelente calidad del Registro, este ajuste nos aseguraba una gran fiabilidad en los resultados. En segundo lugar, se ha compensado la ausencia de niños muertos antes del primer día de vida en 1890,1900, 1910 y 1930, ya que sabemos que este subregistro se produce de forma sistemática a partir de 1880 en el Registro Civil de Baracaldo. Para ello se ha aplicado un cálculo basado en la recta de regresión $\mathrm{y}=0,0043+0,0239 \mathrm{x}$ aplicada en la reconstrucción de las tablas de vida de España en 1900 por el profesor D.Reher - con quien tenemos una enorme deuda metodológica en todo el proceso hasta aquí narrado sobre la estimación de la esperanza de vidaen donde «X» es la mortalidad entre 1 y 364 días, calculada a partir de los nacimientos y defunciones, e «y» es la mortalidad en las primeras 24 horas de vida. Por lo tanto, la mortalidad infantil sería $\mathrm{qo}=\mathrm{x}+\mathrm{y}$.

En cualquier caso hemos tenido la ocasión de comprobar la bondad de la estructura por edades de los padrones utilizados a través de dos vías. Al contrastar las estimaciones del qo y del 4q1 realizadas por las dos vías (a través el registro civil y a través del $\mathrm{m}(\mathrm{x})$ de la tabla de mortalidad), se ha podido confirmar la gran cercanía de los valores, lo cual confirma las fiabilidad de los padrones en su estructura de población. Por otra parte, hemos tenido la oportunidad de contrastar la estructura por edades del padrón municipal, con la estructura por edades del censo publicado por el INE, y se ha comprobado que se da una mayor proporción de niños pequeños de 0 a 4 años en el padrón trabajado por nosotros que en el resumen censal, lo cual refuerza la utilización de nuestra fuente.

\section{Apéndice III: La calidad del Registro Civil en las partidas de mortalidad}

La fuente utilizada para el estudio de las causas de muerte en Baracaldo ha sido el Registro Civil. Dado el gran volumen de población del municipio que estamos trabajando, decidimos realizar unos cortes temporales y realizar un vaciado completo de todos los datos disponibles en cada partida de defunción. El criterio seguido para escoger en qué lugar se hace el corte es el de la posibilidad de disponer para la misma fecha de padrones municipales que nos permitirían ofrecer tasas específicas de mortalidad por edad a la vez que por causa de muerte. Así pues, hemos vaciado cinco años alrededor de las fechas en que se realizaron los padrones, como son 1890 , 
1900, 1910 y 1930. En el caso de 1877 hemos utilizado el resumen de la estructura por edades del censo elaborado por el Instituto de Geografía y Estadística y publicado por el INE ya que está disponible para esta localidad. Consideramos que son fechas muy representativas de la evolución de la ciudad.

Respecto a la calidad de los datos, cabe resaltar que se presentan muy regulares en lo que respecta a lo que podemos denominar las variables básicas como son la edad y la causa de muerte. Consideramos que el nivel de calidad es claramente satisfactorio. Como se ve en la Tabla 1, los casos en los que no consta la edad no superan en ningún caso el uno por ciento. Respecto a las causas de defunción se puede observar que claramente mejora el diagnóstico a lo largo del tiempo; los casos en los que este dato no consta, es ilegible o no se encuentra causa conocida de muerte, tienen un nivel que no llega al tres por ciento salvo para el primer corte.

Tabla 1: Número de casos y porcentajes de ausencia de datos en el Registro Civil de Baracaldo

\begin{tabular}{lccc}
\hline & Núm. de casos & No consta la edad & Sin diagnóstico \\
\hline & & $\%$ & $\%$ \\
\cline { 2 - 4 } 1877 & 630 & 0,47 & 9,84 \\
1890 & 2286 & 0,70 & 2,58 \\
1900 & 2276 & 0,00 & 1,66 \\
1910 & 2136 & 0,09 & 1,21 \\
1930 & 2093 & 0,28 & 2,19 \\
\hline
\end{tabular}

Se ha estimado en qué grupos de edad recaía esta falta de diagnóstico, ya que la calidad de nuestros resultados varía si este error se encuentra aleatoriamente repartido entre la población o bien se concentra en alguno de ellos. El resultado de este test nos llama la atención sobre el grupo de los niños, muy especialmente sobre los menores de un año, en el corte de 1877. Este resultado no es extraño si se tiene en cuenta que la vida y la muerte de los niños empieza a ser importante médica y socialmente precisamente en este período. Encontramos que el $76 \%$ de las partidas sin causa de muerte se corresponde con niños menores de un año que murieron con horas de vida o antes de los primeros treinta días de vida. Por esta razón han sido tratados dentro del grupo de mortalidad infantil endógena, ligado a malformación o problemas derivados del parto. Después de este ajuste el porcentaje de partidas sin diagnóstico en este corte censal queda sensiblemente reducido a un 4,15\%. En el resto de los cortes la falta de diagnóstico se encuentra más uniformemente repartida. 


\section{MERCEDES ARBAIZA VILALLONGA}

\section{BIBLIOGRAFÍA}

ARBAIZA, M. (1994a), Estrategias familiares y transición demográfica en Vizcaya, 1825-1930, Tesis doctoral inédita. Universidad del País Vasco.

ARBAIZA, M. (1994b), «Movimientos migratorios y economías familiares en el norte de España (1877-1910)», Boletín de la Asociación de Demografia Histórica, vols. XII y XIII.

Arbaiza, M.; Guerrero, A.; PARejA, A. (1995), La transición de la mortalidad infantil en Vizcaya, etapas y contrastes territoriales. Comunicación al IV Congreso de la Asociación de Demografía Histórica, Bilbao.

Bernabéu Mestre, J. (s.f.), Evolución de la mortalidad en Pego (1838-1936). Análisis semántico-documental, Facultad de Medicina, Universidad de Alicante.

BERNABÉU MESTRE, J. (1991), «Enfermedad y población: Una aproximación crítica a la epidemiología histórica española», Revisiones en Salud Pública, vol. 2.

BERnABÉU MESTRE, J. (1991), «Estadística demográfico-sanitaria», en ARTOLA, M. (dir.), Enciclopedia de Historia de España, Madrid, vol. V.

BERNABÉu MESTRE, J. (1992), «Fuentes para el estudio de la mortalidad en la España del siglo XIX. Las estadísticas demográfico-sanitarias», en Centro Nacional de Epidemiología (Ed.), Las estadísticas demográfico-sanitarias, Madrid, Inst. de Salud Carlos III/Min. de Sanidad y Consumo.

BERNABÉU MESTRE, J. (1995), Enfermedad y población: Introducción a los problemas y métodos de la epidemiología histórica, Valencia, Seminario de Estudios sobre la Ciencia.

BRESCHI, M., y POZzI, L. (1992), «Un problema di demografia differenziale: mortalità infantile e condizione socio-economica», Actas del II Congreso Italo-Iberico di Demografia Storica, Sabona.

BURNETT, J. (1991), «Housing and the Decline of Mortality», en SCHOFIELD, R.; REHER, D. S., y BIDEAU, A. (Eds.), The Decline of Mortality in Europe, Oxford.

CASElli, G. (1991), «Health Transition and Cause-specific Mortality», en SCHOFIELD, R.; REHER, D. S., y BIDEAU, A. (Eds.), The Decline of Mortality in Europe, Oxford.

FERNÁNDEZ DE PINEDO, E. (1992), «Beneficios, salarios y nivel de vida obrero en una gran empresa siderúrgica vasca, Altos Hornos de Vizcaya (1902-1927). Una primera aproximación», $R e$ vista de Historia Industrial, vol.1.

GóMEZ REDONDO, R. (1992), La mortalidad infantil española en el siglo XX, Madrid.

GONZÁLEZ MARTínEZ, G. (1988), «Aportaciones al estudio del problema de la vivienda en Vizcaya durante la dictadura de Primo de Rivera», en A.A.V.V., 25 años de la Facultad de Filosofía y Letras. II Estudios de Geografia e Historia, Bilbao, Universidad de Deusto.

GONZÁlez PORTILla, M., (1970), La población de la zona minera y de la Ría de Bilbao en el s. XIX. Baracaldo un ejemplo de paso de una demografia de Antiguo Régimen a la revolución industrial, Tesis de licenciatura, Universidad de Valencia.

GonZÁlez PoRTilla, M. (1977), «Los orígenes de la sociedad capitalista en el País Vasco. Transformaciones económicas y sociales en Vizcaya», Saoiak, 1.

GonzÁlez Ugarte, M. E. (1994), «Mortalidad e industrialización en el País Vasco, 1860 1930», Boletín de la Asociación de Demografia Histórica, vol. XII-1. 
CAUSAS SOCIALES DE LA MORTALIDAD DURANTE LA INDUSTRIALIZACIÓN VIZCAÍNA...

LiVI-BACCI, M. (1988), Ensayo sobre la historia demográfica europea. Población y alimentación en Europa, Barcelona.

LUNN, P. G. (1991), «Nutrition, Immunity, and Infection», en SCHOFIELD, R.; REHER, D. S., y BIDEAU, A. (Eds.), The Decline of Mortality in Europe, Oxford.

Martínez Navarro, J. F.; Martínez, O.; Sanz Ortiz, C.; Pérez de la Paz, J. (1995), «El proceso de cambio de la mortalidad infantil en el siglo XX en España» en Actas del IV Congreso de Demografia Histórica, Bilbao.

MCKeown, T. (1977), El crecimiento moderno de la población, Madrid.

MERCER, A. (1990), Disease, Mortality and Population Transition. Epidemiological-Demographic Change in England since the Eighteenth Century as Part of a Global Phenomenon, Leicester.

PERDIGUERO, E. (1993), «Causas de muerte y relación entre conocimiento científico y conocimiento popular», Boletín de la Asociación de Demografía Histórica, vol XI-3.

PÉrez CAStroviejo, P. Ma . (1992), Clase obrera y niveles de vida en las primeras fases de la industrialización vizcaína, Madrid.

PÉREZ-FuENTES, P. (1991), «El discurso higienista y la moralización de la clase obrera en la primera industrialización vasca», Historia Contemporánea, vol. 5, Monográfico: Historia Social y Mentalidades.

PÉREZ-FUENTES, P. (1993), Vivir y morir en las minas. Estrategias familiares y relaciones de género en la primera industrialización vizcaína 1877-1913, Bilbao.

PÉREZ MOREDA, V. (1980), Las crisis de mortalidad en la España interior, siglos XVI-XIX, Madrid.

PÉREZ MOREDA, V. (1988), «Hambre, mortalidad y crecimiento demográfico en las poblaciones de la Europa preindustrial», Revista de Historia Económica, vol. IV, $\mathrm{N}^{\circ} 3$.

Ramos Calvo, P. M., (1988), «Aportaciones de Euskalherria a la inoculación antivariólica», Actas de II Congreso Mundial Vasco, Bilbao.

RodRíGUEz OCAÑA, E. (1995), «La construcción de la salud infantil. Ciencia, Medicina y Educación en la transición de la mortalidad en España», IV Congreso de la Asociación de Demografia Histórica, Bilbao.

SCHOFIELD, R., y REHER, D. S., (1991) «The Decline of Mortality in Europe», en SCHOFIELD, R., REHER, D. S. y BIDEAU, A. (Eds.), The Decline of Mortality in Europe, Oxford.

SHRYOCK S. H. y SIEGELÑ J. S, (1977), The Methods and Materials of Demography, New York.

URRUTIKoETXEA, J. (1986), «Mortalidad de crisis en la Guipúzcoa del siglo XVIII. La Guerra de la Convención», Ernaroa, vol. 1.

VIllanUEVA EDo, A. (1988), «Las instituciones de la lucha antituberculosa en Vizcaya (18821957)», Actas II Congreso Mundial Vasco, Bilbao.

Woods, R., y WoODWARD, J. (Eds.) (1984), Urban Disease and Mortality in Nineteenth Century England, New York. 